\title{
Semiempirical Double-Hybrid Density Functional with Improved Description of Long-Range Correlation
}

\author{
Tobias Benighaus, Robert A. DiStasio, Jr., Rohini C. Lochan, Jeng-Da Chai, and \\ Martin Head-Gordon*
}

Department of Chemistry, University of California, and Chemical Sciences Division, Lawrence Berkeley National Laboratory, Berkeley, California 94720

Received: October 29, 2007; In Final Form: January 5, 2008

\begin{abstract}
The recently proposed new family of "double-hybrid" density functionals [Grimme, S. J. Chem. Phys. 2006, 124,34108 ] replaces a fraction of the semi-local correlation energy by a non-local correlation energy expression that employs the Kohn-Sham orbitals in second-order many-body perturbation theory. These functionals have provided results of high accuracy over a wide range of properties but fail to accurately describe longrange van der Waals interactions. In this work, a distance-dependent scaling factor for the non-local correlation energy is introduced to address this problem, and two new double-hybrid density functionals are proposed. The new functionals are optimized with the finite cc-pVTZ basis on training sets of atomization energies and intermolecular interaction energies. They are compared against (scaled) second-order Møller-Plesset perturbation theories and popular density functionals including the hybrid-GGA functional B3-LYP and the first double-hybrid functional (B2-PLYP). Tests are performed on an extensive set including reaction energies, barrier heights, weakly interacting complexes, transition-metal systems, molecular geometries, and harmonic vibrational frequencies. Within the cc-pVTZ atomic orbital basis, we have demonstrated the ability to find a parametrization scheme which is simultaneously able to describe thermochemistry and weakly bound systems with a satisfactory degree of accuracy.
\end{abstract}

\section{Introduction}

In the past decades, Kohn-Sham density functional theory (KS-DFT) developed into the most widely used method for electronic structure calculations in condensed matter physics and quantum chemistry. ${ }^{1,2}$ In combination with the favorable scaling of its computational costs with system size, the reliability provided by DFT is the main reason for this success. ${ }^{3}$ Although approximate density functionals cannot be improved systematically, Perdew et al. categorized their development into five different stages assigned to "rungs" of a metaphorical "Jacob's ladder". ${ }^{4}$ The first two rungs of this ladder correspond to the local spin-density approximation (LSD) and the generalized gradient approximation (GGA). On the next two rungs, the information in the kinetic energy density (meta-GGAs) and exact exchange (hybrid- or hyper-GGAs) is used to improve the performance of KS-DFT. While the benefits of the kinetic energy density are perhaps only limited,,$^{-7}$ the admixing of about $20 \%$ exact exchange ${ }^{8}$ provides an empirically supported improvement in accuracy for various properties. ${ }^{3}$ On the fifth rung, density functionals make use of the information in the virtual orbitals to include non-local electron correlation, and KS versions of coupled-cluster ${ }^{9,10}$ and second-order MøllerPlesset perturbation theory (MP2) $)^{11-13}$ have been proposed. However, these methodologies have not yet reliably demonstrated a superior performance ${ }^{13}$ and will suffer from far higher computational costs compared to standard KS-DFT. ${ }^{4}$

Recently, a new family of "double-hybrid" density functionals was proposed that employs the occupied and virtual KS orbitals in second-order many-body theory to replace a fraction of the

* To whom correspondence should be addressed. E-mail: mhg@cchem. berkeley.edu. semi-local GGA correlation. The introduction of non-local correlation in the first double-hybrid functional B2-PLYP yielded high accuracy in thermochemistry as well as in the prediction of molecular structure. ${ }^{14-16}$ By construction, that is, with the information in the virtual orbitals, these double-hybrid functionals have the potential to give an accurate description of dispersion effects. Present density functionals up to the fourth rung of complexity fail to describe dispersion effects even qualitatively correctly. These observations have been made more than 10 years ago ${ }^{17,18}$ and still hold for modern density functionals ${ }^{19,20}$ despite occasional claims to the contrary. ${ }^{21}$ In fact, dispersion interactions have a non-negligible influence on the properties of many interesting chemical systems such as proteins, ${ }^{22}$ DNA double helices, ${ }^{23}$ and the DNA-intercalator complex. ${ }^{24}$ Therefore, an accurate account of dispersion interactions is essential to make meaningful predictions of their structure and reactivity.

Kohn et al. ${ }^{25}$ and Misquitta et al. ${ }^{26}$ proposed general schemes to describe dispersion interactions in DFT, but their computational costs prohibit application of these methods to larger, chemically interesting molecules. Empirical potentials of the $C_{6} R^{-6}$ type proved to be a cost-efficient alternative to include dispersion forces in DFT (DFT-D), which provides accurate results in many cases. ${ }^{27-31}$ As a drawback of this approach, empirical $C_{6}$ parameters have to be determined for each atom pair, and damping functions have to be adjusted for each functional/basis set combination. ${ }^{32}$ To circumvent this problem, Becke and Johnson combined an ab initio calculation of the $C_{6}, C_{8}$ and $C_{10}$ coefficients $^{33}$ with a parametrically adjusted density functional to a new DFT-D methodology. ${ }^{34}$ However, all interatom potentials act solely on the ionic cores and do not influence the electronic structure and dependent electronic 
properties. As a consequence, Rothlisberger et al. suggested modeling dispersion forces in DFT with dispersion-optimized atom-based effective potentials. ${ }^{35}$

The goal of this work is to investigate whether or not it is possible to modify fifth-rung double-hybrid density functionals to describe dispersion interactions accurately without the need to additionally incorporate empirical atom-atom van der Waals interactions. To this end, two new functionals will be developed that are optimized both for atomization energies and intermolecular interactions. They are double-hybrid functionals, where the strength of the second-order perturbation correction is allowed to smoothly increase with distance, following a similar idea first tried for scaling the opposite spin second-order correlation energy. ${ }^{36}$ The performance of the new functionals is assessed in comparison to well-established density functionals and second-order perturbation theory methods. The popular hybrid-GGA B3-LYP $8,37,38$ and the first double-hybrid functional B2-PLYP were selected for comparison to DFT methods.

Spin-component-scaled MP2 (SCS-MP2), ${ }^{39}$ scaled opposite spin MP2 (SOS-MP2), ${ }^{40}$ and modified opposite spin MP2 (MOS-MP2) ${ }^{36}$ introduced empirical scaling factors into MP2 theory and improved the accuracy for the description of reaction energies, atomization energies, barrier heights, and molecular geometries. Therefore, these methods and the standard MP2 method $^{41}$ (employing the resolution-of-the-identity approximation $^{42-45}$ ) were also chosen for comparison. A recent communication from our group pointed out that these scaling factors are dependent on the property of interest and the basis set employed, leading to the reparametrized SCS(MI)-MP2 method ${ }^{46}$ that describes molecular interactions accurately. For the description of molecular interaction energies, our new functionals will additionally be assessed in comparison to this method.

\section{Technical Details}

For all calculations, a developmental version of our quantum mechanical software package, Q-CHEM 3.0, was used. ${ }^{47}$ All closed-shell systems were treated restricted, and for open-shell systems, the unrestricted formalism was used. In the perturbative correlation treatment, the resolution-of-the-identity (RI) ${ }^{42,43}$ and the frozen core approximations were used for the two-electron integrals, except for the B2-PLYP functional that correlates all electrons in the perturbative correlation energy. If not stated otherwise, Dunning's correlation-consistent cc-pVTZ basis set ${ }^{48}$ and the corresponding auxiliary basis set ${ }^{49}$ were used for all calculations. Indeed, the new functionals introduced here are therefore specifically designed to be used with this basis. Intermolecular binding energies were corrected for basis set superposition error using the standard counterpoise correction of Boys and Bernardi. ${ }^{50}$ The SG- 1 grid with 50 radial points and 194 angular points per radial point was used for numerical quadrature. ${ }^{51}$ The threshold for the DIIS error vector utilized in the SCF convergence was set to $10^{-8}$ a.u., accompanied by an integral thresholding value of $10^{-12}$ a.u.

\section{Theory and Parametrization}

Our present approach is a modification of the B2-PLYP functional, a semiempirical version of Kohn-Sham perturbation theory (KSPT). It can be viewed as formally based on the exact KSPT by Görling and Levy ${ }^{11,12}$ but uses a much simpler ansatz. In its first step, a standard self-consistent KS-DFT calculation is performed using a hybrid functional of the form

$$
E_{\mathrm{XC}}^{\mathrm{GGA}}=c_{\mathrm{X}} E_{\mathrm{X}}^{\mathrm{HF}}+\left(1-c_{\mathrm{X}}\right) E_{\mathrm{X}}^{\mathrm{B} 88}+c_{\mathrm{LYP}} E_{\mathrm{C}}^{\mathrm{LYP}}
$$

where $E_{\mathrm{X}}^{\mathrm{B} 88}$ and $E_{\mathrm{C}}^{\mathrm{LYP}}$ denote the common exchange and correlation functionals by Becke ${ }^{52}$ and Lee, Yang, and Parr, ${ }^{53}$ respectively. $E_{\mathrm{X}}^{\mathrm{HF}}$ is the exact Hartree-Fock exchange energy, and $c_{\mathrm{X}}$ and $c_{\mathrm{LYP}}$ are empirical scaling parameters. Subsequently, the resulting orbitals and orbital eigenvalues are used for a MP2like perturbative correlation energy expression

$$
E_{\mathrm{C}}^{\mathrm{PT} 2}=\frac{1}{4} \sum_{i j}^{\text {occ }} \sum_{a b}^{\text {vir }} \frac{|(i a|\hat{g}| j b)-(i b|\hat{g}| j a)|^{2}}{\epsilon_{i}+\epsilon_{j}-\epsilon_{a}-\epsilon_{b}} \quad \text { with } \hat{g}=\frac{1}{r}
$$

Here, $i$ and $j$ label occupied and $a$ and $b$ virtual orbitals and orbital eigenvalues $\epsilon$. The self-consistent part of the B2-PLYP functional in eq 1 is finally augmented by the perturbative correlation energy

$$
E_{\mathrm{B} 2-\mathrm{PLYP}}=E_{\mathrm{XC}}^{\mathrm{GGA}}+c_{\mathrm{PT} 2} E_{\mathrm{C}}^{\mathrm{PT} 2}
$$

The value of $c_{\mathrm{PT} 2}$ has been set to $1-c_{\mathrm{LYP}}$. The two global scaling factors $c_{\mathrm{X}}$ and $c_{\mathrm{LYP}}$ were determined empirically against the heat of formations of the G2/97 data set as 47\% B88 exchange and $73 \%$ LYP correlation. Consequentially, the MP2like correlation energy $E_{\mathrm{C}}^{\mathrm{PT} 2}$ is scaled by only $27 \%$, which yields high accuracy for most systems but is insufficient for the description of van der Waals (vdW) interactions. For the $\pi$-stacked benzene dimer, for instance, only $10 \%$ of the interaction energy is recovered by the B2-PLYP functional. ${ }^{14}$

The intent of our approach is to cure the long-range problem in the B2-PLYP functional that stems from this rather small scaling factor for the perturbative correlation energy. Our idea is to determine and use a scaling factor that depends on the interelectronic distance rather than a simple constant factor. Therefore, we define a "modified" two-electron operator, $\hat{g}_{\omega}(r)$

$$
\hat{g}_{\omega}(r)=\frac{1}{r}+c_{\omega} \frac{\operatorname{erf}(\omega r)}{r}
$$

leading to a set of "modified" integrals

$\left(i a\left|\hat{g}_{\omega}\right| j b\right)=\int \mathrm{d} r \int \mathrm{d} r^{\prime} \phi_{i}(r) \phi_{a}(r) \hat{g}_{\omega}\left(r-r^{\prime}\right) \phi_{j}\left(r^{\prime}\right) \phi_{b}\left(r^{\prime}\right)$

in the expression for the perturbative correlation energy in eq 2. The error function was used previously to separate the Coulomb operator $(1 / r)$ into a singular but rapidly decaying part erfc $(\omega r) / r$ and a nonsingular and slowly decaying part $\operatorname{erf}(\omega r) / r$ to improve computational efficiency ${ }^{54,55}$ or reduce basis set requirements. ${ }^{56}$ For our purposes, we use the slowly decaying part to introduce a distance-dependent scaling of the MP2 energy. It is worthwhile to point out here that the parameter $c_{\omega}$ determines the weight that is given to the long-range correlation, while $\omega$ determines the distance at which the asymptotic limit $\hat{g}_{\omega}(r) \rightarrow\left(1+c_{\omega}\right) \hat{g}(r)$ is reached. Previously, this operator has successfully been used in a similar application to introduce a distance-dependent scaling of the opposite spin MP2 energy. ${ }^{36}$ The modification of the two-electron operator necessitates a reoptimization of the global scaling factor $c_{\mathrm{PT} 2}$ for the perturbative correlation energy, and the equation $c_{\mathrm{PT} 2}+$ $c_{\text {LYP }}=1$ is certainly no longer valid. Due to the convincing performance of the B2-PLYP functional, we decided to leave the hybrid-GGA in eq 1 unchanged and optimize exclusively the new empirical parameters $c_{\text {PT2 }}, \omega$, and $c_{\omega}$. Hence, the 


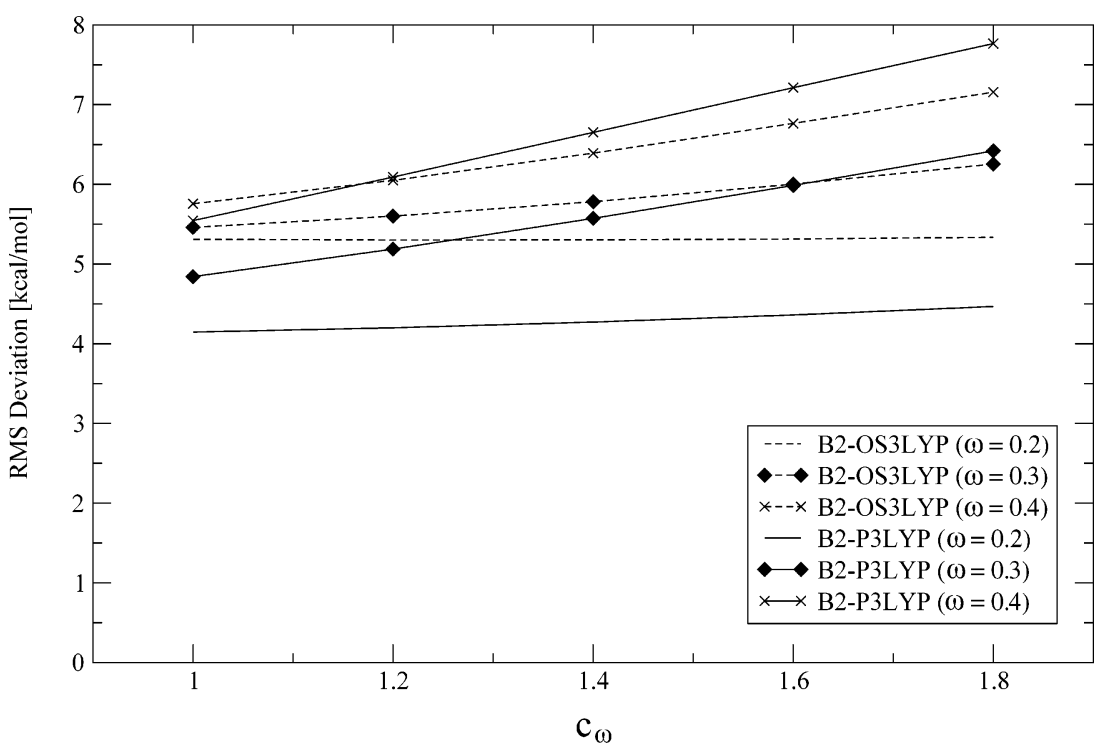

Figure 1. Root-mean-square deviations for the atomization energies of the G2/97 set with the B2-P3LYP and B2-OS3LYP functionals as a function of $c_{\omega}$ for $\omega=0.2,0.3$ and 0.4 .

exchange-correlation energy expression for the new functional is given by

$$
\begin{aligned}
E_{\mathrm{B} 2-\mathrm{P} 3 \mathrm{LYP}}=0.53 E_{\mathrm{X}}^{\mathrm{HF}}+0.47 E_{\mathrm{X}}^{\mathrm{B} 88}+0.73 E_{\mathrm{C}}^{\mathrm{LYP}}+ \\
c_{\mathrm{PT} 2} E_{\mathrm{C}}^{\mathrm{PT} 2}\left(\omega, c_{\omega}\right)
\end{aligned}
$$

with

$$
E_{\mathrm{C}}^{\mathrm{PT} 2}\left(\omega, c_{\omega}\right)=\frac{1}{4} \sum_{i j}^{\mathrm{occ}} \sum_{a b}^{\text {vir }} \frac{\left|\left(i a\left|\hat{g}_{\omega}\right| j b\right)-\left(i b\left|\hat{g}_{\omega}\right| j a\right)\right|^{2}}{\epsilon_{i}+\epsilon_{j}-\epsilon_{a}-\epsilon_{b}}
$$

We denote this functional B2-P3LYP to indicate that this is a modification of the B2-PLYP functional which introduces three additional parameters to describe the perturbative correlation contribution.

One major drawback of fifth-rung functionals based on MP2like correlation terms, like B2-PLYP and B2-P3LYP, is their fifth-order scaling with respect to system size. Therefore, we propose a second functional that uses only the opposite spin (OS) component of the MP2 correlation energy. It has been shown that the OS correlation energy ${ }^{40}$ and its analytical gradient ${ }^{57}$ can be evaluated with algorithms that scale only with the fourth power of system size but provide results of similar or improved accuracy compared to standard MP2 theory. While OS approaches to date have been based on a HF wave function, ${ }^{36,58}$ it is possible that a similar or even improved accuracy can be achieved with a KS reference wave function. Once again, the SCF part remains untouched, leading to the following expression for the exchange-correlation energy

$$
\begin{aligned}
E_{\mathrm{B} 2-\mathrm{OS} 3 \mathrm{LYP}}=0.53 E_{\mathrm{X}}^{\mathrm{HF}}+0.47 E_{\mathrm{X}}^{\mathrm{B} 88}+0.73 E_{\mathrm{C}}^{\mathrm{LYP}}+ \\
c_{\mathrm{OS}} E_{\mathrm{C}}^{\mathrm{OS}}\left(\omega, c_{\omega}\right)
\end{aligned}
$$

with

$$
E_{\mathrm{C}}^{\mathrm{OS}}\left(\omega, c_{\omega}\right)=\sum_{i a}^{\alpha} \sum_{j b}^{\beta} \frac{\left|\left(i a\left|\hat{g}_{\omega}\right| j b\right)\right|^{2}}{\epsilon_{i}+\epsilon_{j}-\epsilon_{a}-\epsilon_{b}}
$$

To indicate that only the OS component of the MP2 correlation energy is evaluated, we call this functional B2-OS3LYP.
The empirical parameters are determined by separate fitting against two different sets. One of them consists of the atomization energies of the G2/97 set of 148 neutral molecules. ${ }^{59,60}$ These energies are dominated by short-range dynamic correlation rather than long-range correlation. In this set, MP2/6-31G*optimized geometries were used in all calculations, and "experimental electronic" atomization energies were chosen as reference. ${ }^{61}$ The S22 set of weakly interacting complexes was selected as a second training set. ${ }^{62}$ This set provides the interaction energies of 22 small- to medium-sized complexes at the $\operatorname{CCSD}(\mathrm{T})$ level extrapolated to the complete basis set limit (CBS). These interaction energies, however, are dominated by long-range correlation. A method that provides accurate results for both of these contrasting sets will very likely be useful for general chemistry applications.

In the first step of our fitting procedure, we determine the values of $c_{\mathrm{PT} 2}$ and $c_{\mathrm{OS}}$ by minimizing the root-mean-square (RMS) deviation for the atomization energies of the G2/97 set for different values of $\omega(0.2,0.3$, and 0.4$)$ and $c_{\omega}(1.0-1.8)$. The RMS deviations of the best fits are illustrated in Figure 1 and suggest two conclusions. First, using only the OS energy is a viable ansatz and shows only marginal reductions in accuracy for $\omega=0.3$ and 0.4 . Second, the introduction of the distance-dependent two-electron operator to account for longrange correlation reduces the accuracy for dynamic correlation. Hence, low values for $\omega$ and $c_{\omega}$ are preferable, but for these parameters, we certainly need values $>0$ to describe long-range correlation. In the following, we will try to find a parametrization with $\omega \leq 0.3$.

In the second step, those values of $c_{\mathrm{PT} 2}$ and $c_{\mathrm{OS}}$ are determined that minimize the RMS deviation in the interaction energies of the S22 set of weakly bound complexes. In Figure 2, the resulting values for $c_{\text {PT2 }}$ are plotted as a function of $c_{\omega}$ for $\omega=$ 0.2 and 0.3 .

Here, it can be observed that we can find two parametrizations that use the same global scaling factor $c_{\text {PT2 }}$ for the description of long-range (S22 set) and short-range (G2/97 set) correlation: $\omega=0.2, c_{\omega}=1.5$ and $\omega=0.3, c_{\omega}=1.0$. The results for the G2/97 atomization energies, as illustrated in Figure 1, suggest that the first parameter set with a smaller $\omega$ value provides higher accuracy for dynamic correlation. Repeating the first step and fitting $c_{\mathrm{PT} 2}$ against the atomization energies 


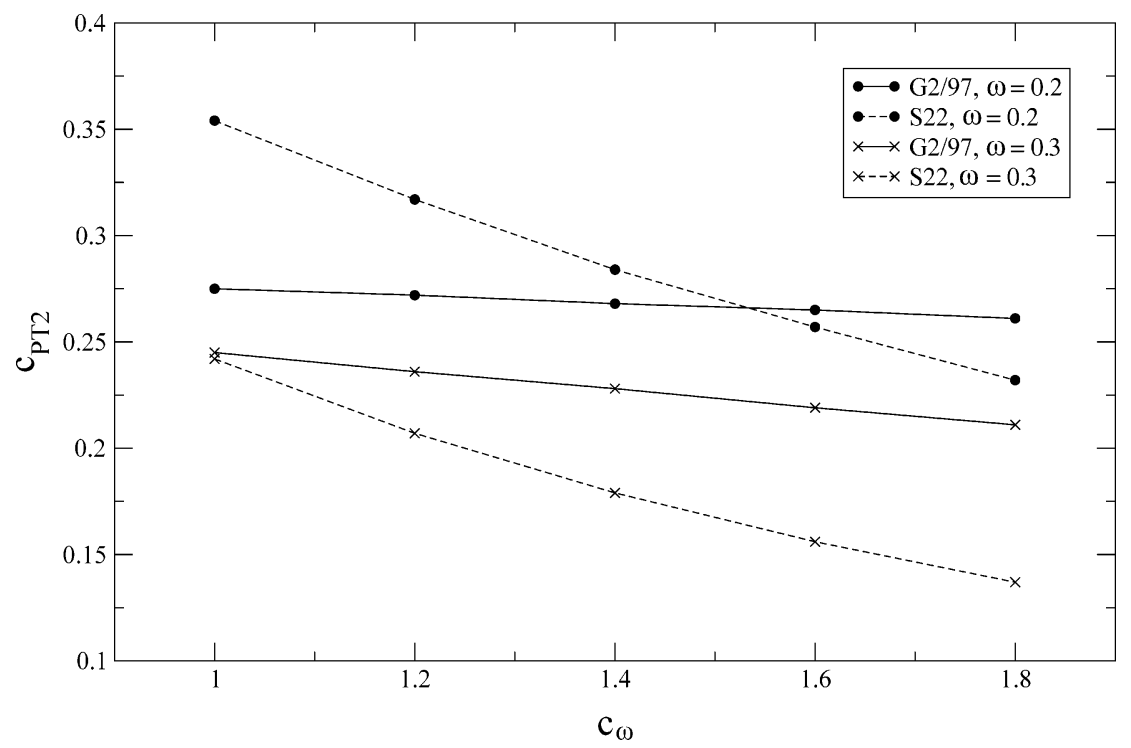

Figure 2. Global scaling factor $c_{\mathrm{PT} 2}$ for B2-P3LYP of the best fits against the G2/97 atomization and S22 interaction energies as a function of $c_{\omega}$ for $\omega=0.2$ and 0.3 .

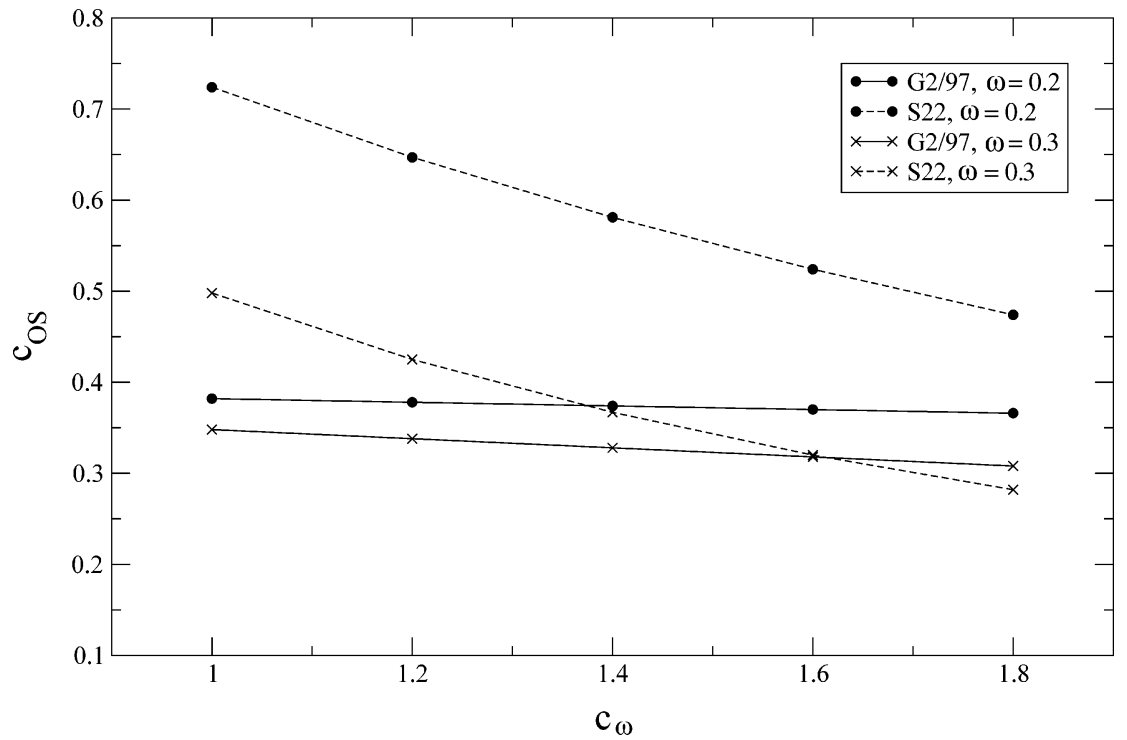

Figure 3. Global scaling factor $c_{\mathrm{OS}}$ for B2-OS3LYP of the best fit against the G2/97 atomization and S22 interaction energies as a function of $c_{\omega}$ for $\omega=0.2$ and 0.3 .

of the $\mathrm{G} 2 / 97$ set with $c_{\omega}$ and $\omega$ fixed at 1.5 and 0.2 , respectively, leads to the final value for $c_{\text {PT2 }}$ of 0.27 .

The parametrization of the B2-OS3LYP functional proceeds in the same way. In Figure 3, the values of $c_{\mathrm{OS}}$ resulting from separate fits against the two training sets are plotted as a function of $c_{\omega}$ for $\omega=0.2$ and 0.3 . Employing an $\omega$ value of 0.2 , no common global scaling factor $c_{\mathrm{OS}}$ can be found unless very high, and therefore physically unreasonable, values for $c_{\omega}$ are chosen. Mildly increasing the slope of the distance-dependent part of the two-electron operator by setting $\omega=0.3$ shifts the point of intersection to $c_{\omega}$ values of approximately 1.6. Subsequently, $c_{\mathrm{OS}}$ is determined to be 0.32 by fitting against the $\mathrm{G} 2 / 97$ atomization energies with $c_{\omega}$ and $\omega$ fixed at 1.6 and 0.3 , respectively.

Summarizing this fitting procedure, we state that we have chosen $\omega$ and $c_{\omega}$ such that the values for all empirical parameters are physically reasonable and that separate fittings against the G2/97 atomization energies and the S22 interaction energies lead to very similar global scaling factors $c_{\mathrm{PT} 2}$ and $c_{\mathrm{OS}}$ for the perturbative correlation energy. All three empirical parameters are strongly interdependent and might be reduced to two or even just one parameter. Thus, we expect no significant improvement from finer screenings of the $\omega$ and $c_{\omega}$ values. The principal limitations of this fitting procedure include the large but finite size of the basis set chosen (cc-pVTZ) and the assumption that the parameters in the Kohn-Sham SCF calculation are independent of the final reoptimization of the three parameters describing the perturbative correlation energy.

Henceforth, we will refer to $\operatorname{B} 2-\operatorname{P} 3 \operatorname{LYP}\left(c_{\mathrm{PT} 2}=0.27, c_{\omega}=1.5\right.$, $\omega=0.2)$ and B2-OS3LYP $\left(c_{\mathrm{OS}}=0.32, c_{\omega}=1.6, \omega=0.3\right)$ as simply B2-P3LYP and B2-OS3LYP, respectively. It should be reemphasized that these functionals were parametrized with the finite cc-pVTZ basis, and they are therefore specifically designed for use with that basis (as the optimized parameters partly compensate for limitations of the basis).

\section{Results and Discussion}

The B2-P3LYP and B2-OS3LYP functionals are hybrids of scaled MP2 and density functional theory. Therefore, their performance is assessed against the MP2 methods RI-MP2, SCS-MP2, SOS-MP2, MOS-MP2, and SCS(MI)-MP2, as well 
TABLE 1: Mean Absolute (MAD), Root-Mean-Square (RMS), Mean Signed (MSD), and Maximum Absolute (MAX) Deviations from Experimental Values (in kcal/mol) for the Atomization Energies of the G2/97 Set. The cc-pVTZ AO Basis Set Is Used

\begin{tabular}{lrrrc}
\hline & MAD & RMS & MSD & MAX \\
\hline RI-MP2 & 7.6 & 9.2 & -3.9 & 23.5 \\
SCS-MP2 & 8.4 & 9.5 & -7.8 & 20.9 \\
SOS-MP2 & 10.1 & 11.7 & -9.8 & 25.7 \\
MOS-MP2 & 17.2 & 19.8 & -17.0 & 39.1 \\
B3-LYP & 4.2 & 6.2 & -2.5 & 29.3 \\
B2-PLYP & 3.4 & 4.6 & -2.2 & 17.7 \\
B2-P3LYP & 3.1 & 4.4 & 0.4 & 15.9 \\
B2-OS3LYP & 4.3 & 6.0 & 0.1 & 22.1
\end{tabular}

as the popular hybrid-GGA B3-LYP. The predecessor functional B2-PLYP is also included in this study.

4.1. The G2/97 and S22 Sets. Table 1 summarizes the errors in the atomization energies of the G2/97 set for the selected scaled and unscaled MP2 and DFT methods and the two new functionals. With a mean absolute deviation (MAD) of $3.1 \mathrm{kcal} /$ mol, B2-P3LYP provides results of similar accuracy to B2PLYP $(\mathrm{MAD}=3.4 \mathrm{kcal} / \mathrm{mol})$. We note that B2-PLYP itself was originally developed to perform best when using a somewhat larger basis than the cc-pVTZ set used here; this accounts for the larger error seen here relative to the original report. ${ }^{14} \mathrm{~B} 2-\mathrm{OS} 3 \mathrm{LYP}(\mathrm{MAD}=4.3 \mathrm{kcal} / \mathrm{mol})$ yields results that are somewhat less accurate than those of B2-PLYP and similar to B3-LYP results $(\mathrm{MAD}=4.2 \mathrm{kcal} / \mathrm{mol}$ ). All MP2 methods are significantly less reliable for atomization energies with MADs ranging from 7.6 (RI-MP2) to $17.2 \mathrm{kcal} / \mathrm{mol}$ (MOSMP2). These large errors partly reflect limitations of the basis set for the MP2 calculations; even the scaled MP2 methods were designed to perform best at the basis set limit.

In Table 2, the deviations in the $\mathrm{S} 22$ set from $\operatorname{CCSD}(\mathrm{T}) /$ CBS reference values for all methods in this study are given. It was pointed out recently that the scaling factors in spincomponent scaled MP2 theory for the description of molecular interactions have to be very different from the optimal factors for short-range correlation that are used in SCS-MP2 and SOSMP2 theory. ${ }^{46}$ In the long range, both spin components contribute almost equally to the intersystem correlation energies of non-overlapping closed-shell systems. Accordingly, the scaling factors in SCS- and SOS-MP2 theory are too small to account properly for vdW interactions, and these methods fail with MADs as great as 1.7 and $2.4 \mathrm{kcal} / \mathrm{mol}$, respectively. B2PLYP suffers from a similar problem. Its scaling factor for the perturbative correlation energy was optimized for the description of short-range correlation and is therefore too small and captures only a fraction of the vdW interaction energy. With a MAD of $2.4 \mathrm{kcal} / \mathrm{mol}$, B2-PLYP performs as unsatisfyingly as SOS-MP2 and is only marginally better than B3-LYP. The inability of current density functionals to describe vdW interactions is well documented and confirmed in this work by a MAD of $3.9 \mathrm{kcal} /$ mol for B3-LYP.

However, unscaled RI-MP2 provides results of acceptable accuracy with a MAD of $0.7 \mathrm{kcal} / \mathrm{mol}$. The results of the SCS(MI)-MP2 method (MAD $=0.3 \mathrm{kcal} / \mathrm{mol})$ indicate that highly accurate results can be obtained within MP2 theory if the scaling parameters are adjusted for the description of molecular interactions and limitations of the basis set employed. Although B2P3LYP and B2-OS3LYP were only indirectly optimized for this set, they show an impressive performance. The MAD for B2P3LYP is as low as $0.4 \mathrm{kcal} / \mathrm{mol}$, reaching almost complete basis set $\operatorname{CCSD}(\mathrm{T})$ quality! Moreover, degradation relative to the SCS(MI)-MP2 results is minimal, though SCS(MI)-MP2 represents the best results possible for this data set using MP2 theory and a cc-pVTZ basis set. The B2-OS3LYP functional has a MAD of $0.4 \mathrm{kcal} / \mathrm{mol}$ and offers high accuracy with only fourth-order computational effort. In this context it is interesting to note that B2-OS3LYP provides results that are significantly superior to those of SOS(MI)-MP2 theory (MAD $=1.4 \mathrm{kcal} /$ mol), which is the best fit of scaled OS MP2 theory to exactly this set. ${ }^{46}$ Moreover, the reasonable results of the MOS-MP2 method $(\mathrm{MAD}=1.1 \mathrm{kcal} / \mathrm{mol})$ underline the possibilities inherent in distance-dependent scaling.

On the basis of these results, we can state that we have defined and parametrized two density functionals that provide accurate results for both training sets, as was the goal.

4.2. Second Test Set. Any quantum chemical method that employs empirical parameters and is trained on a specific set of molecules has to be evaluated on a different set. Therefore, we will use a second test set to evaluate our functionals and compare their performance to the scaled MP2 methods and the selected density functionals. This set comprises 25 main-group reactions, 14 ionic systems (proton affinities, ionization potentials, and electron affinities), 6 transition-metal reactions, 20 barrier heights (16 hydrogen transfer reactions, 4 heavy-atom transfer reactions), and 13 weakly bound complexes.

Experimental values or highly accurate theoretical values were selected as reference. Entries 1-16 were taken from our previous SOS-MP2 paper, ${ }^{40}$ and reference values were derived from experimental atomization energies; ${ }^{61}$ entries $18-45$ were mainly taken from the original B2-PLYP work. ${ }^{14}$ Geometries were optimized at the MP2/6-31G* level of theory. For the isomerization reaction ${ }^{63}$ in entry 25 and all transition-metal reactions ${ }^{64,65}$ (entries 40-45), experimental values were used as reference. Electron affinities (entries 36-39) were calculated using the aug-cc-pVTZ basis with diffuse basis functions. ${ }^{48}$ Barrier heights were mainly taken from the HTBH38/04 ${ }^{66}$ and NHTBH38/0467 databases. The weakly bound complexes were chosen from publications by Tsuzuki et al. ${ }^{68-70}$ (entries 66-70 and 73-75) and Hobza et al. ${ }^{62,71}$ (entries 71, 72, and 76-78).

In Table 3, the results for the 78 reactions and a statistical analysis for the complete set and three subsets (reactions, barrier heights, and interaction energies of weakly bound complexes) are given. Considering the overall performance, one finds that all double-hybrid functionals provide very accurate results. Among them, the B2-P3LYP and B2-OS3LYP functionals gives the most accurate results, with a MAD as low as $3.1 \mathrm{kcal} / \mathrm{mol}$. The B2-PLYP functionals performs marginally worse and yields a MAD of $3.2 \mathrm{kcal} / \mathrm{mol}$. Compared to B3-LYP (MAD $=4.3$ $\mathrm{kcal} / \mathrm{mol}$ ), this corresponds to a reduction in the MAD of $28 \%$ for B2-P3LYP and B2-OS3LYP. MOS-MP2 is the best scaled MP2 method in this study, with a MAD of $3.8 \mathrm{kcal} / \mathrm{mol}$, followed by SCS-MP2 (MAD $=4.1 \mathrm{kcal} / \mathrm{mol})$, SOS-MP2 $(\mathrm{MAD}=4.2 \mathrm{kcal} / \mathrm{mol})$, and unscaled RI-MP2 $(\mathrm{MAD}=4.3$ $\mathrm{kcal} / \mathrm{mol}$ ). As noted before, these MP2 results will partly reflect basis set limitations.

For the subset of reaction energies (including ionic and transition-metal systems), the B2-PLYP functional shows the best performance $(\mathrm{MAD}=3.4 \mathrm{kcal} / \mathrm{mol})$ and is marginally better than B2-OS3LYP (MAD = $3.5 \mathrm{kcal} / \mathrm{mol})$ and B2-P3LYP $(\mathrm{MAD}=3.6 \mathrm{kcal} / \mathrm{mol})$. With MADs ranging from 3.5 (SOSMP2) to $3.9 \mathrm{kcal} / \mathrm{mol}$ (MOS-MP2), all scaled MP2 methods improve significantly upon the unscaled RI-MP2 method (MAD $=5.3 \mathrm{kcal} / \mathrm{mol}$ ). All double-hybrid functionals provide more reliable results for this subset than the B3-LYP functional (MAD $=3.9 \mathrm{kcal} / \mathrm{mol})$. 
TABLE 2: Calculated Interaction Energies of the S22 Set Relative to CCSD(T)/CBS Values in kcal/mol; Relative Deviations in Percent Are Given in Parentheses. The cc-pVTZ AO Basis Set Is Used

\begin{tabular}{|c|c|c|c|c|c|c|c|c|c|c|}
\hline \multirow[b]{2}{*}{ complex } & \multirow[b]{2}{*}{$\Delta E_{\mathrm{ref}}$} & \multicolumn{9}{|c|}{ deviation $^{a}$} \\
\hline & & RI-MP2 ${ }^{b}$ & SCS-MP2 ${ }^{b}$ & SOS-MP2 $2^{b}$ & MOS-MP2 & $\mathrm{SCS}(\mathrm{MI})-\mathrm{MP}^{b}$ & B3-LYP & B2-PLYP & B2-P3LYP & B2-OS3LYP \\
\hline $\begin{array}{l}\left(\mathrm{NH}_{3}\right)_{2} \\
\left(C_{2 h}\right)\end{array}$ & -3.2 & $0.4(13)$ & $0.8(25)$ & $1.0(31)$ & $0.7(21)$ & $0.3(9)$ & $0.9(28)$ & $0.6(19)$ & $0.3(10)$ & $0.3(11)$ \\
\hline $\begin{array}{l}\left(\mathrm{H}_{2} \mathrm{O}\right)_{2} \\
\left(C_{S}\right)\end{array}$ & -5.0 & $0.6(12)$ & $1.0(20)$ & $1.2(25)$ & $1.1(21)$ & $0.2(4)$ & $0.5(10)$ & $0.4(8)$ & $0.3(6)$ & $0.4(8)$ \\
\hline $\begin{array}{l}\text { (formic acid })_{2} \\
\left(C_{2 h}\right)\end{array}$ & -18.6 & $1.7(9)$ & $3.3(18)$ & $4.2(22)$ & $3.5(19)$ & $-0.4(-2)$ & $1.1(6)$ & $1.1(6)$ & $0.4(2)$ & $0.9(5)$ \\
\hline $\begin{array}{l}(\text { formamide })_{2} \\
\left(C_{2 h}\right)\end{array}$ & -16.0 & $1.7(11)$ & $3.0(19)$ & $3.7(23)$ & $2.8(18)$ & $0.3(2)$ & $2.0(12)$ & $1.6(10)$ & $0.7(5)$ & $0.9(5)$ \\
\hline $\begin{array}{l}(\text { uracil })_{2} \\
\left(C_{2 h}\right)\end{array}$ & -20.7 & $1.9(9)$ & 3.7 (18) & $4.7(23)$ & $3.4(17)$ & $-0.2(-1)$ & $2.8(14)$ & $2.2(11)$ & $0.3(2)$ & $0.9(4)$ \\
\hline $\begin{array}{l}\text { 2-pyridoxine } \cdot 2 \text {-aminopyridine } \\
\left(C_{1}\right)\end{array}$ & -16.7 & $0.8(5)$ & $2.8(17)$ & $3.8(23)$ & $2.3(14)$ & $-0.2(-1)$ & $2.9(17)$ & $1.9(11)$ & $-0.5(-3)$ & $-0.2(-1)$ \\
\hline $\begin{array}{l}\text { adenine } \cdot \text { thymine } \mathrm{WC} \\
\left(C_{1}\right)\end{array}$ & -16.4 & $1.5(9)$ & $3.3(20)$ & $4.2(26)$ & $2.8(17)$ & $0.5(3)$ & $3.6(22)$ & $2.4(15)$ & $-0.1(-1)$ & $0.3(2)$ \\
\hline $\begin{array}{l}\left(\mathrm{CH}_{4}\right)_{2} \\
\left(D_{3 d}\right)\end{array}$ & -0.5 & $0.2(40)$ & $0.4(68)$ & $0.4(83)$ & $0.2(43)$ & $0.3(49)$ & $0.9(171)$ & $0.6(115)$ & $0.3(57)$ & $0.3(48)$ \\
\hline $\begin{array}{l}\left(\mathrm{C}_{2} \mathrm{H}_{4}\right)_{2} \\
\left(D_{2 d}\right)\end{array}$ & -1.5 & $0.4(24)$ & $0.9(56)$ & $1.1(73)$ & $0.5(36)$ & $0.4(25)$ & $2.1(138)$ & $1.3(89)$ & $0.6(38)$ & $0.5(34)$ \\
\hline $\begin{array}{l}\text { benzene } \cdot \mathrm{CH}_{4} \\
\left(C_{3}\right)\end{array}$ & -1.5 & $0.1(6)$ & $0.7(46)$ & $1.0(66)$ & $0.3(19)$ & $0.2(12)$ & $2.3(152)$ & $1.4(95)$ & $0.4(24)$ & $0.3(20)$ \\
\hline $\begin{array}{l}(\text { benzene })_{2} \\
\left(C_{2 h}\right)\end{array}$ & -2.7 & $-1.0(-38)$ & $0.9(33)$ & $1.9(68)$ & $-0.6(-21)$ & $-0.3(-11)$ & $6.5(238)$ & $3.8(138)$ & $-0.5(-19)$ & $-0.6(-21)$ \\
\hline $\begin{array}{l}(\text { pyrazine })_{2} \\
\left(C_{S}\right)\end{array}$ & -4.4 & $-1.0(-23)$ & $1.1(24)$ & $2.1(48)$ & $-0.4(-10)$ & $-0.3(-7)$ & $6.9(156)$ & $4.0(90)$ & $-0.2(-5)$ & $-0.4(-9)$ \\
\hline $\begin{array}{l}(\text { uracil })_{2} \\
\left(C_{2}\right)\end{array}$ & -10.1 & $1.0(10)$ & $3.5(35)$ & $4.8(47)$ & $1.8(18)$ & $0.7(7)$ & $9.2(91)$ & $5.8(57)$ & $0.8(8)$ & $0.7(7)$ \\
\hline $\begin{array}{l}\text { indole } \cdot \text { benzene } \\
\left(C_{1}\right)\end{array}$ & -5.2 & $-1.2(-23)$ & $1.7(33)$ & $3.2(61)$ & $-0.5(-10)$ & $-0.3(-5)$ & $9.9(190)$ & $5.8(112)$ & $-0.6(-12)$ & $-0.6(-12)$ \\
\hline $\begin{array}{l}\text { adenine } \cdot \text { thymine stack } \\
\left(C_{1}\right)\end{array}$ & -12.2 & $-0.1(-1)$ & $3.8(31)$ & $5.7(46)$ & $1.0(8)$ & $0.2(2)$ & 13.7 (112) & $8.2(67)$ & $0.3(3)$ & $0.1(1)$ \\
\hline $\begin{array}{l}\text { ethene } \cdot \text { ethine } \\
\left(C_{2 v}\right)\end{array}$ & -1.5 & $0.1(7)$ & $0.4(27)$ & $0.6(38)$ & $0.3(17)$ & $0.0(-2)$ & $0.8(54)$ & $0.5(34)$ & $0.1(5)$ & $0.1(4)$ \\
\hline $\begin{array}{l}\text { benzene } \cdot \mathrm{H}_{2} \mathrm{O} \\
\left(C_{S}\right)\end{array}$ & -3.3 & $0.3(11)$ & $0.9(28)$ & $1.2(37)$ & $0.6(19)$ & $0.2(6)$ & $2.1(64)$ & $1.4(41)$ & $0.6(18)$ & $0.5(16)$ \\
\hline $\begin{array}{l}\text { benzene } \cdot \mathrm{NH}_{3} \\
\left(C_{S}\right)\end{array}$ & -2.4 & $0.2(9)$ & $0.8(34)$ & $1.1(46)$ & $0.4(19)$ & $0.2(9)$ & $2.2(95)$ & $1.4(61)$ & $0.5(21)$ & $0.4(18)$ \\
\hline $\begin{array}{l}\text { benzene } \cdot \mathrm{HCN} \\
\left(C_{S}\right)\end{array}$ & -4.5 & $-0.1(-3)$ & $0.7(16)$ & $1.2(26)$ & $0.3(7)$ & $-0.6(-13)$ & $2.4(53)$ & $1.3(30)$ & $0.1(3)$ & $0.1(2)$ \\
\hline $\begin{array}{l}(\text { benzene })_{2} \\
\left(C_{2 v}\right)\end{array}$ & -2.7 & $-0.3(-10)$ & $0.8(30)$ & $1.4(50)$ & $0.1(2)$ & $-0.2(-6)$ & 3.7 (134) & $2.2(79)$ & $-0.2(-7)$ & $-0.1(-4)$ \\
\hline $\begin{array}{l}\text { indole } \cdot \text { benzene } t \text {-shape } \\
\left(C_{1}\right)\end{array}$ & -5.7 & $-0.4(-8)$ & $1.2(20)$ & $2.0(34)$ & $0.1(2)$ & $-0.4(-6)$ & $5.1(88)$ & $2.9(51)$ & $-0.4(-6)$ & $-0.2(-4)$ \\
\hline $\begin{array}{l}(\mathrm{phenol})_{2} \\
\left(C_{1}\right)\end{array}$ & -7.1 & $0.3(5)$ & $1.7(24)$ & $2.4(33)$ & $1.0(14)$ & $0.2(3)$ & $4.1(58)$ & $2.5(36)$ & $0.1(2)$ & $0.3(4)$ \\
\hline MAD & & 0.7 & 1.7 & 2.4 & 1.1 & 0.3 & 3.9 & 2.4 & 0.4 & 0.4 \\
\hline $\mathrm{MAPD}^{c}$ & & 13 & 29 & 42 & 17 & 8 & 87 & 53 & 12 & 11 \\
\hline RMS & & 0.9 & 2.1 & 2.8 & 1.6 & 0.3 & 5.1 & 3.1 & 0.4 & 0.5 \\
\hline MSD & & 0.3 & 1.7 & 2.4 & 1.0 & 0.0 & 3.9 & 2.4 & 0.2 & 0.2 \\
\hline MAX & & 1.9 & 3.8 & 5.7 & 3.5 & 0.7 & 13.7 & 8.2 & 0.8 & 0.9 \\
\hline
\end{tabular}

${ }^{a}$ Deviation $=$ calc. - ref. ${ }^{b}$ The RI-MP2, SCS-MP2, SOS-MP2, and SCS(MI)-MP2 results were taken from DiStasio et al. ${ }^{46}{ }^{c}$ Mean absolute percent deviation.

The best performance for the prediction of barrier heights with a MAD of $3.0 \mathrm{kcal} / \mathrm{mol}$ is shown by the B2-PLYP functional, although it was parametrized for equilibrium properties only. The two new functionals perform a bit less well and yield MADs of 3.7 and $4.0 \mathrm{kcal} / \mathrm{mol}$, respectively. This corresponds to an increase in the MAD of 25 and $35 \%$ relative to B2-PLYP. This impairment might result from the fixed SCF parameters and could possibly be reduced by refitting the SCF parameters. However, B2-P3LYP and B2-OS3LYP still outperform the other remaining methods. B3-LYP and all MP2 methods demonstrate relatively inaccurate performance in this subset, with MADs of 5.0 (MOS-MP2) to $6.6 \mathrm{kcal} / \mathrm{mol}$ (SOSMP2) and maximum deviations up to almost $20 \mathrm{kcal} / \mathrm{mol}$ for all MP2 methods (which again might be somewhat improved with a larger basis set).

The advantages inherent in distance-dependent scaling are evident in the description of weakly bound complexes. The B2P3LYP functional yields the most accurate and balanced results in this subset, with a MAD of $0.6 \mathrm{kcal} / \mathrm{mol}$ and a maximum absolute deviation (MAX) of only $1.5 \mathrm{kcal} / \mathrm{mol}$. This is a moderate improvement upon RI-MP2 theory, which has MAD and MAX values of 0.8 and $3.2 \mathrm{kcal} / \mathrm{mol}$. The B2-OS3LYP functional performs almost as well as B2-P3LYP, with MAD and MAX values of 0.6 and $1.7 \mathrm{kcal} / \mathrm{mol}$, respectively. Both functionals clearly outperform the B2-PLYP functional, which suffers from its constant scaling factor, as evident in a MAD of $2.4 \mathrm{kcal} / \mathrm{mol}$ (i.e., 4 times larger). For the dispersion complexes (entries 73-78), B2-PLYP rarely captures more than $50 \%$ of the interaction energy. B3-LYP gives a reasonable description of hydrogen-bonded complexes but performs poorly for the dispersion complexes, leading to a MAD of $3.7 \mathrm{kcal} / \mathrm{mol}$. Among the scaled MP2 methods, MOS-MP2 gives the best results for this subset, and while SCS-MP2 and SOS-MP2 are poorer with MAD values of 2.0 and $2.4 \mathrm{kcal} / \mathrm{mol}$, respectively, MOS-MP2 demonstrates an improved performance with a MAD of $1.4 \mathrm{kcal} / \mathrm{mol}$, corroborating the reasonable results for the S22 set.

Finally, the performance of these novel functionals in describing two simple atom-atom complexes $\left(\mathrm{Ne}_{2}\right.$ and $\left.\mathrm{Ar}_{2}\right)$ is evaluated (see Supporting Information). While the RI-MP2, MOS-MP2, B2-P3LYP, and B2-OS3LYP methods provide results that are qualitatively correct, the scaled MP2 methods 
TABLE 3: Calculated Energetic Data of the Second Test Set Relative to High-Quality Calculations or Experimental Results (in kcal/mol). The cc-pVTZ AO Basis Set Is Used. For the Weakly Bound Complexes, the Relative Deviations in Percent Are Given in Parentheses

\begin{tabular}{|c|c|c|c|c|c|c|c|c|c|c|}
\hline \multirow[b]{2}{*}{ \# } & \multirow[b]{2}{*}{ reaction } & \multirow[b]{2}{*}{$\Delta E_{\text {ref }}$} & \multicolumn{8}{|c|}{ deviation $^{a}$} \\
\hline & & & RI-MP2 & SCS-MP2 & SOS-MP2 & MOS-MP2 & B3-LYP & B2-PLYP & B2-P3LYP & B2-OS3LYP \\
\hline \multicolumn{11}{|c|}{ Main-Group Reactions } \\
\hline 1 & $\mathrm{~F}_{2} \mathrm{O}+\mathrm{H}_{2} \rightarrow \mathrm{F}_{2}+\mathrm{H}_{2} \mathrm{O}$ & -66.6 & -3.4 & -1.9 & -1.2 & 0.5 & 5.2 & 2.1 & 3.0 & 4.5 \\
\hline 2 & $\mathrm{H}_{2} \mathrm{O}_{2}+\mathrm{H}_{2} \rightarrow 2 \mathrm{H}_{2} \mathrm{O}$ & -86.2 & -2.6 & 0.2 & 1.6 & 3.8 & 4.8 & 2.2 & 3.0 & 5.8 \\
\hline 3 & $\mathrm{CO}+\mathrm{H}_{2} \rightarrow \mathrm{CH}_{2} \mathrm{O}$ & -4.2 & -0.2 & 1.1 & 1.7 & 2.2 & -3.8 & -2.5 & -1.8 & -1.3 \\
\hline 4 & $\mathrm{~N}_{2} \mathrm{O}+\mathrm{H}_{2} \rightarrow \mathrm{N}_{2}+\mathrm{H}_{2} \mathrm{O}$ & -79.6 & 5.6 & 2.0 & 0.2 & 3.9 & 7.8 & 7.3 & 10.6 & 11.6 \\
\hline 5 & $\mathrm{CH}_{2} \mathrm{CO}+2 \mathrm{H}_{2} \rightarrow \mathrm{CH}_{2} \mathrm{O}+\mathrm{CH}_{4}$ & -42.6 & 1.2 & 0.0 & -0.6 & 1.7 & 2.4 & 1.5 & 3.0 & 3.7 \\
\hline 6 & $\mathrm{HCOOH} \rightarrow \mathrm{CO}_{2}+\mathrm{H}_{2}$ & 0.7 & -1.8 & -2.1 & -2.2 & -2.7 & -0.1 & -0.7 & -1.5 & -1.9 \\
\hline 7 & $\mathrm{C}_{2} \mathrm{H}_{2}+\mathrm{HF} \rightarrow \mathrm{C}_{2} \mathrm{H}_{3} \mathrm{~F}$ & -27.5 & 2.2 & 1.8 & 1.6 & 3.1 & -5.1 & -2.5 & -1.7 & -1.4 \\
\hline 8 & $\mathrm{HCN}+\mathrm{H}_{2} \mathrm{O} \rightarrow \mathrm{CO}+\mathrm{NH}_{3}$ & -12.9 & 2.7 & 1.4 & 0.7 & 2.5 & -0.6 & 0.5 & 1.1 & 1.5 \\
\hline 9 & $\mathrm{HCN}+\mathrm{NH}_{3} \rightarrow \mathrm{N}_{2}+\mathrm{CH}_{4}$ & -37.1 & -2.1 & -3.4 & -4.1 & -3.7 & 0.3 & -0.9 & -0.8 & -1.0 \\
\hline 10 & $\mathrm{CO}+\mathrm{CH}_{4} \rightarrow \mathrm{CH}_{3} \mathrm{CHO}$ & 3.5 & -0.4 & 1.9 & 3.0 & 2.5 & -2.7 & -1.7 & -1.7 & -1.3 \\
\hline 11 & $2{ }^{1} \mathrm{CH}_{2} \rightarrow \mathrm{C}_{2} \mathrm{H}_{4}$ & -198.3 & -13.4 & -4.3 & 0.2 & -1.0 & -4.4 & -7.2 & -7.9 & -4.1 \\
\hline 12 & $\mathrm{CH}_{3} \mathrm{ONO} \rightarrow \mathrm{CH}_{3} \mathrm{NO}_{2}$ & -2.4 & -5.3 & -3.7 & -2.9 & -3.1 & -1.8 & -2.5 & -2.4 & -2.6 \\
\hline 13 & cyclopropene $\rightarrow$ propyne & -23.5 & -0.4 & -1.1 & -1.4 & -1.7 & 0.0 & -0.7 & -0.8 & -1.1 \\
\hline 14 & oxirane $\rightarrow \mathrm{CH}_{3} \mathrm{CHO}$ & -26.3 & 0.6 & -0.2 & -0.6 & -0.5 & -1.5 & -1.3 & -1.3 & -1.5 \\
\hline 15 & $\mathrm{C}_{2} \mathrm{H}_{4}+{ }^{1} \mathrm{CH}_{2} \rightarrow \mathrm{C}_{3} \mathrm{H}_{6}$ & -114.3 & -8.4 & -2.5 & 0.5 & -0.1 & -1.0 & -3.5 & -4.2 & -1.5 \\
\hline 16 & $\mathrm{O}_{3}+\mathrm{CH}_{4} \rightarrow 2 \mathrm{H}_{2} \mathrm{O}+\mathrm{CO}$ & -158.0 & 6.0 & 3.8 & 2.7 & 9.3 & 6.2 & 8.9 & 14.3 & 18.9 \\
\hline 17 & ${ }^{3} \mathrm{CH}_{2} \rightarrow{ }^{1} \mathrm{CH}_{2}$ & $9.1^{b}$ & 5.1 & -0.9 & -3.9 & -3.1 & 2.6 & 3.2 & 2.7 & -1.0 \\
\hline 18 & $\mathrm{~F}_{2}+\mathrm{H}_{2} \rightarrow 2 \mathrm{HF}$ & -132.9 & -7.8 & -2.4 & 0.3 & 3.1 & 6.8 & 2.9 & 4.0 & 8.5 \\
\hline 19 & $\mathrm{CO}+3 \mathrm{H}_{2} \rightarrow \mathrm{CH}_{4}+\mathrm{H}_{2} \mathrm{O}$ & -62.3 & -2.1 & 1.7 & 3.6 & 5.6 & -1.8 & -1.5 & 0.1 & 2.8 \\
\hline 20 & $\mathrm{~N}_{2}+3 \mathrm{H}_{2} \rightarrow 2 \mathrm{NH}_{3}$ & -36.7 & 1.3 & 5.1 & 7.1 & 10.5 & -4.1 & -1.5 & 0.6 & 3.9 \\
\hline 21 & ${ }^{1} \mathrm{CH}_{2}+\mathrm{H}_{2} \rightarrow \mathrm{CH}_{4}$ & -128.2 & -7.2 & -2.1 & 0.4 & 1.1 & -2.5 & -4.3 & -4.0 & -1.0 \\
\hline 22 & $\mathrm{C}_{2} \mathrm{H}_{2}+\mathrm{H}_{2} \rightarrow \mathrm{C}_{2} \mathrm{H}_{4}$ & -48.8 & 2.1 & 2.4 & 2.5 & 4.2 & -1.6 & -0.5 & 0.5 & 1.3 \\
\hline 23 & $\mathrm{CO}+\mathrm{H}_{2} \mathrm{O} \rightarrow \mathrm{CO}_{2}+\mathrm{H}_{2}$ & -6.7 & -4.1 & -1.9 & -0.8 & -1.4 & -8.0 & -7.1 & -7.7 & -7.2 \\
\hline 24 & allene $\rightarrow$ propyne & -1.5 & -3.5 & -2.9 & -2.6 & -2.7 & 3.6 & 0.8 & 0.6 & 1.2 \\
\hline 25 & $n$-octane $\rightarrow$ tetramethylbutane ${ }^{c}$ & -1.9 & -2.1 & 1.1 & 2.8 & -0.6 & 10.4 & 5.4 & 2.3 & 1.8 \\
\hline \multicolumn{11}{|c|}{ Ionic Systems } \\
\hline 26 & $\mathrm{HF}+\mathrm{H}^{+} \rightarrow \mathrm{H}_{2} \mathrm{~F}^{+}$ & -122.2 & 0.9 & 0.2 & -0.2 & 0.2 & -1.5 & -1.4 & -1.3 & -1.7 \\
\hline 27 & $\mathrm{H}_{2} \mathrm{O}+\mathrm{H}^{+} \rightarrow \mathrm{H}_{3} \mathrm{O}^{+}$ & -172.3 & 1.0 & 0.0 & -0.5 & 0.5 & -0.6 & -0.2 & 0.2 & 0.0 \\
\hline 28 & $\mathrm{NH}_{3}+\mathrm{H}^{+} \rightarrow \mathrm{NH}_{4}^{+}$ & -212.5 & 1.0 & -0.5 & -1.3 & 0.3 & -1.2 & -1.2 & -0.6 & -0.9 \\
\hline 29 & $\mathrm{H}_{2}^{+} \rightarrow \mathrm{H}_{2}^{+}\left(r=2 r_{\mathrm{e}}\right)^{d}$ & 36.3 & 0.0 & 0.0 & 0.0 & 0.0 & -14.6 & -8.3 & -8.3 & -8.3 \\
\hline 30 & $\mathrm{Li}^{-} \rightarrow \mathrm{Li}^{+}$ & 124.3 & -7.1 & -8.4 & -9.1 & -7.2 & 5.4 & 1.8 & 1.9 & 1.9 \\
\hline 31 & $\mathrm{Be} \rightarrow \mathrm{Be}^{+}$ & 214.9 & -10.9 & -7.4 & -5.6 & -1.8 & -4.8 & -7.2 & -5.3 & 0.4 \\
\hline 32 & $\mathrm{C} \rightarrow \mathrm{C}^{+}$ & 259.6 & 1.7 & -1.3 & -2.8 & -2.3 & -12.5 & 1.8 & 2.0 & 0.7 \\
\hline 33 & $\mathrm{~F} \rightarrow \mathrm{F}^{+}$ & 401.7 & 1.4 & 1.1 & 1.0 & -4.5 & 5.5 & -0.7 & -0.6 & -1.4 \\
\hline 34 & $\mathrm{O} \rightarrow \mathrm{O}^{+}$ & 313.8 & -1.5 & 0.7 & 1.9 & -2.7 & 11.1 & 2.7 & 2.8 & 3.3 \\
\hline 35 & $\mathrm{~N} \rightarrow \mathrm{N}^{+}$ & 335.3 & 2.9 & -3.0 & -5.9 & -5.8 & 2.2 & -1.2 & -1.0 & -3.9 \\
\hline 36 & $\mathrm{~B} \rightarrow \mathrm{B}^{-}$ & -6.4 & 0.5 & 3.9 & 5.6 & 3.9 & -4.2 & 0.3 & -1.7 & 0.0 \\
\hline 37 & $\mathrm{Cl} \rightarrow \mathrm{Cl}^{-}$ & -83.4 & -2.9 & -0.6 & 0.5 & -1.8 & -1.4 & 0.8 & -1.2 & -1.7 \\
\hline 38 & $\mathrm{Si} \rightarrow \mathrm{Si}^{-}$ & -31.9 & -0.1 & 4.1 & 6.2 & 4.5 & 0.8 & 2.8 & 0.0 & 2.6 \\
\hline 39 & $\mathrm{Al} \rightarrow \mathrm{Al}^{-}$ & -10.2 & 1.4 & 3.7 & 4.8 & 3.2 & -0.4 & 2.4 & 0.7 & 0.8 \\
\hline \multicolumn{11}{|c|}{ Transition-Metal Reactions } \\
\hline 40 & $\mathrm{Ni}(\mathrm{CO})_{4} \rightarrow \mathrm{Ni}(\mathrm{CO})_{3}+\mathrm{CO}^{e}$ & 27.0 & 30.6 & 18.3 & 12.2 & 12.7 & -6.2 & 9.1 & 12.2 & 7.2 \\
\hline 41 & $\mathrm{Ni}(\mathrm{CO})_{3} \rightarrow \mathrm{Ni}(\mathrm{CO})_{2}+\mathrm{CO}^{e}$ & 30.0 & 26.9 & 18.7 & 14.6 & 15.6 & 1.8 & 11.8 & 13.3 & 9.7 \\
\hline 42 & $\mathrm{Cr}(\mathrm{CO})_{6} \rightarrow \mathrm{Cr}(\mathrm{CO})_{5}+\mathrm{CO}^{e}$ & 39.0 & 23.4 & 13.8 & 9.0 & 11.6 & -2.6 & 5.6 & 8.9 & 6.7 \\
\hline 43 & $\mathrm{Cr}(\mathrm{CO})_{5} \mathrm{H}_{2} \rightarrow \mathrm{Cr}(\mathrm{CO})_{5}+\mathrm{H}_{2}{ }^{e}$ & 17.5 & 16.1 & 10.5 & 7.7 & 9.1 & 1.1 & 5.6 & 6.8 & 5.2 \\
\hline 44 & $\mathrm{Cu}_{2} \rightarrow 2 \mathrm{Cu}^{e}$ & 46.8 & -9.4 & -10.7 & -11.4 & -7.8 & -3.2 & -4.4 & -1.3 & 2.7 \\
\hline 45 & $\mathrm{Ni}_{2} \rightarrow 2 \mathrm{Ni}^{e}$ & 47.1 & -6.2 & -8.4 & -9.4 & -5.1 & 4.8 & -11.8 & -8.6 & -4.2 \\
\hline & MAD(1-45) & & 5.4 & 3.7 & 3.5 & 4.0 & 4.0 & 3.4 & 3.6 & 3.7 \\
\hline & RMS(1-45) & & 8.7 & 5.7 & 5.0 & 5.3 & 5.3 & 4.6 & 5.2 & 5.3 \\
\hline & $\operatorname{MSD}(1-45)$ & & 0.4 & 0.6 & 0.6 & 1.4 & 0.0 & 0.2 & 0.7 & 1.5 \\
\hline & MAX (1-45) & & 30.6 & 18.7 & 14.6 & 15.6 & 14.6 & 11.8 & 14.3 & 18.9 \\
\hline \multicolumn{11}{|c|}{ Barrier Heights } \\
\hline 46 & $\mathrm{Cl}+\mathrm{H}_{2} \rightarrow \mathrm{HCl}+\mathrm{H}$ & 8.7 & 0.2 & 4.0 & 5.9 & 3.8 & -4.0 & -2.3 & -3.2 & -2.4 \\
\hline 47 & $\mathrm{H}+\mathrm{H}_{2} \mathrm{O} \rightarrow \mathrm{OH}+\mathrm{H}_{2}$ & 21.2 & 8.5 & 6.1 & 4.9 & 3.0 & -9.3 & -4.1 & -4.6 & -6.3 \\
\hline 48 & $\mathrm{CH}_{3}+\mathrm{H}_{2} \rightarrow \mathrm{CH}_{4}+\mathrm{H}$ & 12.1 & 0.9 & 2.6 & 3.4 & 2.2 & -3.5 & -2.0 & -2.5 & -2.5 \\
\hline 49 & $\mathrm{CH}_{3}+\mathrm{H}_{2} \mathrm{O} \rightarrow \mathrm{OH}+\mathrm{CH}_{4}$ & 19.6 & 3.7 & 4.1 & 4.4 & 1.7 & -7.1 & -4.1 & -5.0 & -5.7 \\
\hline 50 & $\mathrm{CH}_{2} \mathrm{OH}+\mathrm{H}_{2} \rightarrow \mathrm{H}+\mathrm{CH}_{3} \mathrm{OH}$ & $16.1^{f}$ & 0.0 & 1.6 & 2.4 & 1.2 & -3.6 & -2.2 & -2.8 & -2.8 \\
\hline 51 & $\mathrm{H}+\mathrm{H}_{2} \rightarrow \mathrm{H}_{2}+\mathrm{H}$ & 9.6 & 3.7 & 3.9 & 4.0 & 3.5 & -5.4 & -2.5 & -2.7 & -3.1 \\
\hline 52 & $\mathrm{H}_{2} \mathrm{O}+\mathrm{NH}_{2} \rightarrow \mathrm{OH}+\mathrm{NH}_{3}$ & 12.7 & 5.7 & 7.9 & 8.9 & 6.8 & -7.0 & -3.5 & -4.7 & -4.1 \\
\hline 53 & $\mathrm{Cl}+\mathrm{CH}_{4} \rightarrow \mathrm{HCl}+\mathrm{CH}_{3}$ & 7.9 & 1.0 & 4.3 & 6.0 & 3.5 & -2.4 & -0.8 & -2.1 & -1.8 \\
\hline 54 & $\mathrm{H}_{2} \mathrm{O}+\mathrm{C}_{2} \mathrm{H}_{5} \rightarrow \mathrm{OH}+\mathrm{C}_{2} \mathrm{H}_{6}$ & 19.9 & 3.9 & 4.2 & 4.3 & 1.5 & -5.8 & -3.3 & -4.4 & -5.2 \\
\hline 55 & $\mathrm{H}+\mathrm{HF} \rightarrow \mathrm{F}+\mathrm{H}_{2}$ & 33.4 & 9.1 & 5.4 & 3.5 & 0.8 & -13.8 & -7.2 & -7.5 & -9.6 \\
\hline 56 & $\mathrm{PH}_{2}+\mathrm{H}_{2} \rightarrow \mathrm{H}+\mathrm{PH}_{3}$ & $23.2^{g}$ & 2.3 & 4.5 & 5.6 & 3.6 & -2.0 & -0.7 & -1.4 & -1.5 \\
\hline 57 & $\mathrm{H}+\mathrm{ClH} \rightarrow \mathrm{HCl}+\mathrm{H}$ & $18.0^{h}$ & 6.4 & 7.3 & 7.7 & 6.2 & -4.6 & -1.1 & -2.2 & -3.1 \\
\hline 58 & $\mathrm{OH}+\mathrm{H} \rightarrow \mathrm{H}_{2}+\mathrm{O}$ & 10.7 & 6.3 & 5.7 & 5.4 & 3.5 & -7.4 & -3.2 & -3.6 & -4.7 \\
\hline 59 & $\mathrm{H}_{2}+\mathrm{HS} \rightarrow \mathrm{H}+\mathrm{H}_{2} \mathrm{~S}$ & 17.3 & 0.9 & 4.1 & 5.6 & 3.4 & -2.6 & -1.3 & -2.3 & -1.9 \\
\hline 60 & $\mathrm{CH}_{4}+\mathrm{NH} \rightarrow \mathrm{NH}_{2}+\mathrm{CH}_{3}$ & $22.4^{g}$ & 2.6 & 4.3 & 5.1 & 4.2 & -5.0 & -2.3 & -3.2 & -3.3 \\
\hline 61 & $\mathrm{H}+\mathrm{N}_{2} \mathrm{O} \rightarrow \mathrm{OH}+\mathrm{N}_{2}$ & 18.1 & 18.7 & 19.4 & 19.7 & 19.2 & -6.2 & -0.6 & -1.1 & -1.0 \\
\hline
\end{tabular}




\begin{tabular}{|c|c|c|c|c|c|c|c|c|c|c|}
\hline \multirow[b]{2}{*}{$\#$} & \multirow[b]{2}{*}{ reaction } & \multirow[b]{2}{*}{$\Delta E_{\text {ref }}$} & \multicolumn{8}{|c|}{ deviation $^{a}$} \\
\hline & & & RI-MP2 & SCS-MP2 & SOS-MP2 & MOS-MP2 & B3-LYP & B2-PLYP & B2-P3LYP & B2-OS3LYP \\
\hline \multicolumn{11}{|c|}{ Barrier Heights (continued) } \\
\hline 62 & $\mathrm{HCN} \rightarrow \mathrm{HNC}$ & 48.2 & 4.0 & 4.2 & 4.2 & 3.2 & -0.5 & 1.0 & 0.3 & 0.3 \\
\hline 63 & $\mathrm{HOCH}_{3}+\mathrm{F}^{-} \rightarrow \mathrm{CH}_{3} \mathrm{~F}+\mathrm{OH}^{-}$ & 17.3 & -8.3 & -7.2 & -6.6 & -8.3 & -14.5 & -12.8 & -14.3 & -15.0 \\
\hline 64 & $\mathrm{CH}_{3}+\mathrm{FCl} \rightarrow \mathrm{CH}_{3} \mathrm{~F}+\mathrm{Cl}$ & 7.4 & 12.4 & 14.3 & 15.3 & 12.9 & -9.0 & -4.4 & -5.7 & -5.5 \\
\hline 65 & $\mathrm{CH}_{3}+\mathrm{C}_{2} \mathrm{H}_{4} \rightarrow \mathrm{CH}_{3} \mathrm{CH}_{2} \mathrm{CH}_{2}$ & 6.9 & 6.3 & 8.4 & 9.5 & 8.5 & -1.0 & 0.2 & -1.0 & -0.7 \\
\hline & $\operatorname{MAD}(46-65)$ & & 5.2 & 6.2 & 6.6 & 5.0 & 5.7 & 3.0 & 3.7 & 4.0 \\
\hline & $\operatorname{RMS}(46-65)$ & & 6.9 & 7.4 & 7.8 & 6.6 & 6.8 & 4.1 & 4.8 & 5.2 \\
\hline & $\operatorname{MSD}(46-65)$ & & 4.4 & 5.4 & 6.0 & 4.2 & -5.7 & -2.9 & -3.7 & -4.0 \\
\hline & $\operatorname{MAX}(46-65)$ & & 18.7 & 19.4 & 19.7 & 19.2 & 14.5 & 12.8 & 14.3 & 15.0 \\
\hline \multicolumn{11}{|c|}{ Weakly Bound Complexes } \\
\hline 66 & $2 \mathrm{HF} \rightarrow(\mathrm{HF})_{2}$ & -4.4 & $1.4(32)$ & $1.7(39)$ & $1.8(42)$ & $1.7(39)$ & $0.9(21)$ & $0.9(21)$ & $0.8(19)$ & $0.9(21)$ \\
\hline 67 & $\mathrm{H}_{2} \mathrm{O}+\mathrm{CH}_{3} \mathrm{OH} \rightarrow \mathrm{H}_{2} \mathrm{O} \cdot \mathrm{CH}_{3} \mathrm{OH}$ & -4.9 & $0.4(7)$ & $0.9(19)$ & $1.2(25)$ & $0.9(18)$ & $0.5(10)$ & $0.3(6)$ & $0.0(1)$ & $0.1(3)$ \\
\hline 68 & $2 \mathrm{CH}_{3} \mathrm{OH} \rightarrow\left(\mathrm{CH}_{3} \mathrm{OH}\right)_{2}$ & -5.5 & $0.5(8)$ & $1.2(23)$ & $1.6(30)$ & $1.1(20)$ & $1.4(26)$ & $0.9(16)$ & $0.3(5)$ & $0.4(7)$ \\
\hline 69 & $\mathrm{HCN}+\mathrm{HF} \rightarrow \mathrm{HCN} \cdot \mathrm{HF}$ & -7.1 & $0.5(8)$ & $1.0(14)$ & $1.2(17)$ & $1.1(16)$ & $0.6(9)$ & $0.5(6)$ & $0.4(6)$ & $0.6(8)$ \\
\hline 70 & $\mathrm{H}_{2} \mathrm{O}+\mathrm{H}_{2} \mathrm{CO} \rightarrow \mathrm{H}_{2} \mathrm{O} \cdot \mathrm{H}_{2} \mathrm{CO}$ & -5.2 & $0.8(15)$ & $1.3(25)$ & $1.6(30)$ & $1.3(25)$ & $1.2(23)$ & $0.8(16)$ & $0.6(11)$ & $0.7(13)$ \\
\hline 71 & 2 formamidine $\rightarrow$ (formamidine $)_{2}$ & -14.4 & $-0.6(-4)$ & $1.1(8)$ & $2.0(14)$ & $1.0(7)$ & $0.3(2)$ & $-0.3(-2)$ & $-1.5(-10)$ & $-1.2(-9)$ \\
\hline 72 & $\mathrm{G}+\mathrm{C} \rightarrow \mathrm{G} \cdot \mathrm{C}(\text { Watson-Crick })^{i}$ & -32.1 & $3.2(10)$ & $5.5(17)$ & $6.6(21)$ & $5.0(16)$ & $5.0(16)$ & $3.9(12)$ & $1.2(4)$ & $1.7(5)$ \\
\hline 73 & $\mathrm{C}_{6} \mathrm{H}_{6}+\mathrm{C}_{2} \mathrm{H}_{2} \rightarrow \mathrm{C}_{6} \mathrm{H}_{6} \cdot \mathrm{C}_{2} \mathrm{H}_{2}$ & -2.8 & $-0.1(-5)$ & $0.6(20)$ & $0.9(32)$ & $0.1(4)$ & $2.2(76)$ & $1.3(44)$ & $0.1(2)$ & $0.0(0)$ \\
\hline 74 & $\mathrm{C}_{6} \mathrm{H}_{6}+\mathrm{C}_{2} \mathrm{H}_{4} \rightarrow \mathrm{C}_{6} \mathrm{H}_{6} \cdot \mathrm{C}_{2} \mathrm{H}_{4}$ & -2.1 & $0.0(-1)$ & $0.8(37)$ & $1.2(56)$ & $0.2(12)$ & $2.7(129)$ & $1.6(78)$ & $0.1(6)$ & $0.1(5)$ \\
\hline 75 & $\mathrm{C}_{6} \mathrm{H}_{6}+\mathrm{CHF}_{3} \rightarrow \mathrm{C}_{6} \mathrm{H}_{6} \cdot \mathrm{CHF}_{3}$ & -4.2 & $0.5(11)$ & $1.4(32)$ & $1.8(43)$ & $0.9(21)$ & $3.4(80)$ & $2.1(51)$ & $0.8(19)$ & $0.7(18)$ \\
\hline 76 & $\mathrm{C}+\mathrm{U} \rightarrow \mathrm{C} \cdot \mathrm{U}(\text { stacked })^{i}$ & -10.4 & $1.2(11)$ & $3.4(32)$ & $4.5(43)$ & $1.8(17)$ & $8.7(83)$ & $5.6(54)$ & $0.7(6)$ & $0.6(6)$ \\
\hline 77 & $\mathrm{G}+\mathrm{C} \rightarrow \mathrm{G} \cdot \mathrm{C}(\text { stacked })^{i}$ & -19.0 & $0.9(5)$ & $4.5(24)$ & $6.3(33)$ & $2.1(11)$ & $12.2(64)$ & $7.5(40)$ & $0.4(2)$ & $0.4(2)$ \\
\hline 78 & $\mathrm{C}+\mathrm{C} \rightarrow \mathrm{C} \cdot \mathrm{C}(\text { stacked })^{i}$ & -9.9 & $1.0(10)$ & $3.3(33)$ & $4.4(45)$ & $1.6(16)$ & $9.7(98)$ & $6.2(62)$ & $0.8(9)$ & $0.8(8)$ \\
\hline & $\operatorname{MAD}(66-78)$ & & 0.8 & 2.0 & 2.7 & 1.4 & 3.7 & 2.4 & 0.6 & 0.6 \\
\hline & $\operatorname{MAPD}(66-78)^{j}$ & & 10 & 25 & 33 & 17 & 49 & 31 & 8 & 8 \\
\hline & $\operatorname{RMS}(66-78)$ & & 1.1 & 2.5 & 3.3 & 1.9 & 5.4 & 3.4 & 0.7 & 0.8 \\
\hline & $\operatorname{MSD}(66-78)$ & & 0.7 & 2.0 & 2.7 & 1.4 & 3.7 & 2.4 & 0.4 & 0.5 \\
\hline & $\operatorname{MAX}(66-78)$ & & 3.2 & 5.5 & 6.6 & 5.0 & 12.2 & 7.5 & 1.5 & 1.7 \\
\hline & MAD(1-78) & & 4.5 & 4.1 & 4.2 & 3.8 & 4.3 & 3.2 & 3.1 & 3.1 \\
\hline & $\operatorname{RMS}(1-78)$ & & 7.4 & 5.8 & 5.6 & 5.3 & 5.6 & 4.3 & 4.6 & 4.6 \\
\hline & $\operatorname{MSD}(1-78)$ & & 1.7 & 2.1 & 2.3 & 2.0 & -1.0 & -0.3 & -0.5 & -0.2 \\
\hline & $\operatorname{MAX}(1-78)$ & & 30.6 & 19.4 & 19.7 & 19.2 & 14.6 & 12.8 & 14.3 & 18.9 \\
\hline
\end{tabular}

${ }^{a}$ Deviation = calc. - ref. ${ }^{b}$ Shavit. ${ }^{72}{ }^{c}$ MP2/6-311G(d,p) geometries. ${ }^{d}$ Exact within the AO basis, $r_{\mathrm{e}}=1.507 \AA .{ }^{e}$ BP86/TZVPP geometries; TZVPP AO basis set. ${ }^{f} \mathrm{Pu}$ et al. ${ }^{73}{ }^{g}$ Dybala-Defratyka et al. ${ }^{74}{ }^{h}$ Lynch et al. ${ }^{75}{ }^{i} \mathrm{C}$ : cytosine; G: guanine; U: uracil. ${ }^{j}$ Mean absolute percent deviation.

(SCS-MP2 and SOS-MP2) as well as B3-LYP and B2-PLYP predict that these complexes are either barely bound or even unbound.

4.3. Geometries and Frequencies. The evaluation of properties other than energies is a vital part of the assessment of any new method. Hence, we test our proposed functionals for three different sets of structural data. Due to the increased computational costs of geometry optimizations and frequency calculations, only the most accurate of the scaled MP2 methods in the previous tests (MOS-MP2) is included. The theoretical derivation of analytical derivatives for double-hybrid functionals was published recently such that analytical first derivatives could be used for all double-hybrids in this study. ${ }^{16}$

The performance for the prediction of covalent bond lengths is tested with the Equilibrium Experimental Test Set (EXTS). ${ }^{44}$ This set comprises 166 symmetry-unique experimental bond lengths of 136 molecules ranging in system size from $\mathrm{H}_{2}$ to benzene, consisting of first and second row atoms. It contains both open- and closed-shell molecules in cationic, anionic, and neutral states. The results of the geometry optimizations of the EXTS are summarized in Table 4 and show that none of the methods have pronounced difficulties in describing covalent bonds. The MADs in the bond lengths for all methods are approximately $1.0 \mathrm{pm}$; only the OS methods perform worse, with MADs of $1.6 \mathrm{pm}$ for B2-OS3LYP and MOS-MP2. The B2-PLYP functional yields the best results for this test set, with a MAD of only $0.8 \mathrm{pm}$. B2-P3LYP performs marginally worse than B3-LYP (MAD = $1.0 \mathrm{pm})$ and B2-PLYP and yields a MAD of $1.2 \mathrm{pm}$. The results for all methods in this study may be deemed satisfactory if we take into account that the test set contains several hard cases, such as $\mathrm{SH}, \mathrm{BCl}, \mathrm{O}_{2}{ }^{+}$and $\mathrm{He}_{2}{ }^{+}$.

To answer the question if B2-P3LYP and B2-OS3LYP can
TABLE 4: Mean Absolute (MAD), Root-Mean-Square (RMS), Mean Signed (MSD), and Maximum Absolute (MAX) Deviations (in pm) from Experimentally Determined Structural Data Found during Geometry Optimization of the EXTS Using the cc-pVTZ AO Basis Set

\begin{tabular}{lcccc}
\hline \multicolumn{1}{c}{ method } & MAD & RMS & MSD & MAX \\
\hline RI-MP2 & 1.0 & 1.5 & 0.3 & 8.8 \\
MOS-MP2 & 1.6 & 2.1 & 1.3 & 6.8 \\
B3-LYP & 1.0 & 1.5 & 0.6 & 7.2 \\
B2-PLYP & 0.8 & 1.2 & 0.5 & 7.8 \\
B2-P3LYP & 1.2 & 1.7 & 1.0 & 7.2 \\
B2-OS3LYP & 1.6 & 2.2 & 1.5 & 8.0
\end{tabular}

provide not only accurate interaction energies but also molecular geometries for weakly bound complexes, we chose seven complexes from the S22 set and optimized their geometries. Four hydrogen-bonded, two dispersion, and one mixed complex were selected. Highly accurate molecular structures optimized on the $\operatorname{CCSD}(\mathrm{T})$ level of theory in combination with a quadruple- $\zeta$ basis set were used as reference geometries. ${ }^{62}$ The results in Table 5 show that B3-LYP describes hydrogen bonds very well but fails severely to describe the vdW bond lengths for the methane and ethene dimer with very large deviations of up to $227 \mathrm{pm}$. MOS-MP2 and RI-MP2 yield results of very similar accuracy. Their description of hydrogen-bonded complexes is slightly inferior to B3-LYP, but they give reliable results for the dispersion complexes. For the hydrogen-bonded complexes, all double-hybrids yield a similar accuracy that is competitive with that of B3-LYP. The dispersion complexes are best described by B2-OS3LYP, which is wrong by less than $2 \mathrm{pm}$, followed by B2-P3LYP with deviations of a few picometers. The B2-PLYP functional overestimates the bond lengths more severely, with deviations of approximately $20 \mathrm{pm}$. 
TABLE 5: Intermolecular Bond Lengths for Seven Weakly Bound Complexes Resulting from Geometry Optimizations Using the cc-pVTZ AO Basis Set Relative to $\operatorname{CCSD}(\mathrm{T}) / \mathrm{QZ}$ Geometries (in pm)

\begin{tabular}{|c|c|c|c|c|c|c|c|}
\hline \multirow[b]{2}{*}{ molecule } & \multicolumn{7}{|c|}{ deviation $^{a}$} \\
\hline & ref. & RI-MP2 & MOS-MP2 & B3-LYP & B2-PLYP & B2-P3LYP & B2-OS3LYP \\
\hline$\left(\mathrm{NH}_{3}\right)_{2}{ }^{b}$ & 250.4 & -4.6 & 1.0 & 0.1 & -1.8 & -3.6 & -2.9 \\
\hline$\left(\mathrm{H}_{2} \mathrm{O}\right)_{2}{ }^{c}$ & 195.2 & -1.6 & 4.1 & -0.8 & -1.3 & -1.6 & -0.6 \\
\hline$\left(\mathrm{HCO}_{2} \mathrm{H}\right)_{2}{ }^{c}$ & 167.0 & -2.2 & 4.7 & -0.9 & -1.0 & -1.8 & -0.1 \\
\hline$\left(\mathrm{HCONH}_{2}\right)_{2}{ }^{c}$ & 184.1 & 1.7 & 3.6 & 2.2 & 0.9 & -0.7 & 0.1 \\
\hline$\left(\mathrm{CH}_{4}\right)_{2}^{d}$ & 371.8 & -1.0 & 0.5 & 227.0 & 20.6 & 0.3 & 0.4 \\
\hline$\left(\mathrm{C}_{2} \mathrm{H}_{4}\right)_{2}{ }^{d}$ & 371.8 & -4.0 & 1.4 & 68.2 & 21.0 & 7.4 & 1.8 \\
\hline $\mathrm{C}_{2} \mathrm{H}_{4} \cdot \mathrm{C}_{2} \mathrm{H}_{2}{ }^{d}$ & 442.2 & -0.3 & 0.0 & 0.1 & 0.0 & 0.0 & -0.1 \\
\hline MAD & & 2.2 & 2.2 & 42.8 & 6.7 & 2.2 & 0.9 \\
\hline RMS & & 2.6 & 2.8 & 89.6 & 11.2 & 3.3 & 1.3 \\
\hline MSD & & -2.2 & 2.2 & 42.3 & 5.5 & 0.0 & -0.2 \\
\hline MAX & & 4.6 & 4.7 & 227.0 & 21.0 & 7.4 & 2.9 \\
\hline
\end{tabular}

${ }^{a}$ Deviation $=$ calc. - ref. ${ }^{b} \mathrm{~N} \cdots \mathrm{H}$ distance. ${ }^{c} \mathrm{O} \cdots \mathrm{H}$ distance. ${ }^{d}$ Distance of the centers of mass of the monomers.

TABLE 6: Comparison of Experimental ${ }^{76}$ and Calculated Harmonic Vibrational Frequencies (in $\mathrm{cm}^{-1}$ ) for 18 Diatomic $^{-1}$ Molecules. The cc-pVTZ AO Basis Set Is Used

\begin{tabular}{|c|c|c|c|c|c|c|c|}
\hline \multirow[b]{2}{*}{ molecule } & \multicolumn{7}{|c|}{ deviation $^{a}$} \\
\hline & $\omega_{\text {exp }}$ & RI-MP2 & MOS-MP2 & B3-LYP & B2-PLYP & B2-P3LYP & B2-OS3LYP \\
\hline $\mathrm{B}_{2}$ & 1051 & 46 & 100 & -45 & -5 & -12 & 45 \\
\hline $\mathrm{BF}$ & 1402 & 15 & 22 & 6 & 13 & 5 & 2 \\
\hline $\mathrm{Br}_{2}$ & 325 & 19 & -6 & 5 & 11 & 2 & -18 \\
\hline $\mathrm{C}_{2}$ & 1855 & 26 & -1 & 20 & -4 & -48 & -54 \\
\hline $\mathrm{CH}$ & 2859 & 83 & 7 & -31 & 24 & 3 & -43 \\
\hline $\mathrm{Cl}_{2}$ & 560 & 18 & -22 & -30 & -9 & -22 & -53 \\
\hline $\mathrm{Cu}_{2}$ & 264 & -11 & -28 & 0 & -2 & -4 & -14 \\
\hline $\mathrm{F}_{2}^{+}$ & 1073 & -194 & -173 & 165 & 6 & -54 & -72 \\
\hline $\mathrm{F}_{2}$ & 917 & 100 & 5 & 135 & 106 & 85 & 17 \\
\hline $\mathrm{HF}$ & 4138 & 42 & 11 & -41 & 7 & -9 & -32 \\
\hline $\mathrm{N}_{2}{ }^{+}$ & 2207 & -110 & -151 & 128 & 3 & -53 & -81 \\
\hline $\mathrm{N}_{2}$ & 2360 & -165 & -164 & 92 & -7 & -58 & -70 \\
\hline $\mathrm{O}_{2}^{+}$ & 1905 & -411 & -296 & 148 & -62 & -137 & -120 \\
\hline $\mathrm{O}_{2}$ & 1580 & -126 & -28 & 46 & -43 & -94 & -41 \\
\hline $\mathrm{OH}$ & 3738 & 82 & 17 & -44 & 17 & -2 & -39 \\
\hline $\mathrm{P}_{2}$ & 781 & -54 & -117 & 20 & -15 & -102 & -174 \\
\hline $\mathrm{S}_{2}$ & 726 & -13 & -19 & -20 & -19 & -65 & -65 \\
\hline SO & 1149 & -11 & 21 & -7 & -32 & -75 & -52 \\
\hline MAD & & 85 & 66 & 55 & 21 & 46 & 55 \\
\hline RMS & & 128 & 104 & 76 & 33 & 61 & 68 \\
\hline MSD & & -37 & -46 & 30 & -1 & -36 & -48 \\
\hline MAX & & 411 & 296 & 165 & 106 & 137 & 174 \\
\hline
\end{tabular}

Overall, the B2-OS3LYP functional shows the highest accuracy with a MAD of $0.9 \mathrm{pm}$.

We conclude this section with a set of harmonic vibrational frequencies of 18 diatomic molecules in Table 6. The overall best performer is the B2-PLYP functional, with a MAD of 21 $\mathrm{cm}^{-1}$, followed by the two new double-hybrid functionals B2P3LYP $\left(\right.$ MAD $\left.=46 \mathrm{~cm}^{-1}\right)$ and B2-OS3LYP $($ MAD $=55$ $\left.\mathrm{cm}^{-1}\right)$. Once again, all double-hybrid functionals yield results of higher (B2-PLYP and B2-P3LYP) or similar (B2-OS3LYP) accuracy compared to that of the B3-LYP functional (MAD = $55 \mathrm{~cm}^{-1}$ ), which is the most accurate among the established methods. The two new functionals underestimate the vibrational frequencies, leading to some impairment of the MAD relative to B2-PLYP.

\section{Conclusions}

In this work, we have investigated whether or not it is possible to significantly improve the otherwise excellent performance of the doubly hybrid B2-PLYP functional for dispersion interactions without the need for an empirical atom-atom van der Waals potential. We did this by developing and exploring two new double-hybrid density functionals for general chemistry applications, B2-P3LYP and B2-OS3LYP, which are derived from the B2-PLYP functional, with modifications to improve the accuracy of dispersion interactions. This was achieved by introducing a distance-dependent scaling of the perturbative correlation energy in the scheme of double-hybrid density functionals. They are parametrized against experimental atomization energies (the G2/97 set) and high-accuracy intermolecular interaction energies (the S22 set) simultaneously. A fixed finite basis, cc-pVTZ, is to be used with B2-P3LYP and B2-OS3LYP. B2-OS3LYP has a simpler form yielding reduced (fourth power of system size) computational cost, while B2-P3LYP scales with the fifth power of molecule size. These newly proposed functionals are applicable to medium-sized molecular systems (100-1000 atoms) that cannot be treated by high-level ab initio methods yet still provide results with higher accuracy than most current DFT functionals. With a quintic dependence on the molecular system size, the applicability of the B2-P3LYP functional is directly comparable to RI-MP2 theory. With comparable accuracy, one can utilize the more computationally efficient B2-OS3LYP functional for even larger molecular systems of interest, with a computational cost most directly comparable to that of SOS-MP2 and MOS-MP2 computations.

The new functionals were assessed against a diverse test set encompassing main-group reactions, ionization potentials, elec- 
tron and proton affinities, transition-metal systems, barrier heights, and interaction energies of weakly bound complexes. B2-P3LYP and B2-OS3LYP largely retain the very robust performance of the B2-PLYP functional for reaction energies and barrier heights. In addition, for the interaction energies of dispersion complexes, for which B2-PLYP was found to be poor, both B2-P3LYP and B2-OS3LYP performed reliably through the use of a distance-dependent two-electron operator. The answer to the question posed in this work is therefore affirmative.

In addition to the energetic data, the performance of the new functionals for the prediction of molecular structures was evaluated against three test sets: an extensive set of experimental covalent bond lengths, a small set of intermolecular distances of weakly bound complexes, and a small set of harmonic vibrational frequencies. The description of covalent bonds and hydrogen bonds poses no serious problems for any method in this study including the two new functionals. For the dispersion complexes, B2-OS3LYP and B2-P3LYP very significantly improved upon the B2-PLYP functional that overestimated the distances by more than $20 \mathrm{pm}$. B2-PLYP performed best for the prediction of vibrational frequencies, but B2-P3LYP and B2-OS3LYP showed only a modest degradation and still retained B3-LYP accuracy.

Finally, it is appropriate to briefly summarize the fitting approach used because it has important implications for the use of B2-P3LYP and B2-OS3LYP. We chose to fit against experimental data using the large but finite cc-pVTZ basis. Since the Kohn-Sham exchange-correlation and the perturbative correlation are converged to different extents in this finite basis, this is admittedly a compromise. As a result, direct use of basis sets that are significantly larger (e.g., cc-pVQZ) will generally not be expected to improve the results; B2-P3LYP and B2OS3LYP are best used with their intended basis set, and one should reparametrize for basis sets that are either significantly larger or smaller. On the basis of both the training and the independent test sets, B2-P3LYP and B2-OS3LYP offer clear advantages for systems in which weak interactions play important roles (i.e., most large molecules) and demonstrate that double-hybrid density functionals can describe van der Waals interactions accurately without relying on empirical atomic dispersion corrections.

Acknowledgment. This work was supported by the U.S. Department of Energy through the Office of Basic Energy Sciences via the Computational Nanoscience Program. T.B. gratefully acknowledges a scholarship by the Studienstiftung des deutschen Volkes (National German Academic Foundation) and would like to thank R. P. Steele for providing the EXTS database and Y. M. Rhee for helpful discussions. M.H.G. is a part-owner of Q-Chem Inc.

Supporting Information Available: Interaction energies. This material is available free of charge via the Internet at http:// pubs.acs.org.

\section{References and Notes}

(1) Kohn, W.; Sham, L. J. Phys. Rev. A 1965, 140, 1133

(2) Parr, R. G.; Yang, W. Density-Functional Theory of Atoms and Molecules; Oxford University Press: Oxford, U.K., 1989.

(3) Koch, W.; Holthausen, M. C. A Chemist's Guide to Density Functional Theory, 2nd ed.; Wiley-VCH: Weinheim, Germany, 2002.

(4) Perdew, J. P.; Ruzsinszky, A.; Tao, J.; Staroverov, V. N.; Scuseria, G. E.; Csonka, G. I. J. Chem. Phys. 2005, 123, 062201.

(5) Boese, A. D.; Martin, J. M. L. J. Chem. Phys. 2004, 121, 3405.

(6) Grimme, S. J. Phys. Chem. A 2005, 109, 3067.
(7) Csonka, G. I.; Ruzsinsky, A.; Tao, J.; Perdew, J. P. Int. J. Quantum Chem. 2005, 101, 506

(8) Becke, A. D. J. Chem. Phys. 1993, 98, 1372.

(9) Bartlett, R. J.; Grabowski, I.; Hirata, S.; Ivanov, S. J. Chem. Phys. 2005, 122, 034104

(10) Bartlett, R. J.; Lotrich, V. F.; Schweigert, I. V. J. Chem. Phys. 2005, 123, 062205 .

(11) Görling, A.; Levy, M. Phys. Rev. B 1993, 47, 13105

(12) Görling, A.; Levy, M. Phys. Rev. A 1994, 50, 196.

(13) Mori-Sanchez, P.; Wu, Q.; Yang, W. J. Chem. Phys. 2005, 123 062204.

(14) Grimme, S. J. Chem. Phys. 2006, 124, 034108.

(15) Schwabe, T.; Grimme, S. Phys. Chem. Chem. Phys. 2006, 8, 4398.

(16) Neese, F.; Schwabe, T.; Grimme, S. J. Chem. Phys. 2007, 126, 124115 .

(17) Kristyan, S.; Pulay, P. Chem. Phys. Lett. 1994, 229, 175 315

(19) Tsuzuki, S.; Lüthi, H. P. J. Chem. Phys. 2000, 114, 3949.

(20) Cerný, J.; Hobza, P. Phys. Chem. Chem. Phys. 2005, 7, 1624.

(21) Xu, X.; Goddard, W. A., III Proc. Natl. Acad. Sci. U.S.A. 2004 101,2673

(22) Vondrášek, J.; Bendová, L.; Hobza, V. K. P. J. Am. Chem. Soc. 2005, 127, 2615

(23) Da̧bkowska, I.; Gonzalez, H. V.; Jureča, P.; Hobza, P. J. Phys. Chem. A 2005, 109, 1131.

(24) Kubař, T.; Hanus, M.; Ryjáček, F.; Hobza, P. Chem.-Eur. J. 2006, $12,280$.

(25) Kohn, W.; Meir, Y.; Makarov, D. E. Phys. Rev. Lett. 1998, 80, 4153.

(26) Misquitta, A. J.; Jeziorski, B.; Szalewicz, K. Phys. Rev. Lett. 2003 , 91, 033201.

(27) Grimme, S. J. Comput. Chem. 2004, 25, 1463.

(28) Zimmerli, U.; Parrinello, M.; Koumoutsakos, P. J. Chem. Phys. 2004, 120, 2693.

(29) Wu, Q.; Yang, W. J. Chem. Phys. 2002, 116, 515.

(30) Wu, X.; Vargas, M. C.; Nayak, S.; Lotrich, V.; Scoles, G. J. Chem. Phys. 2001, 115, 8748 .

(31) Schwabe, T.; Grimme, S. Phys. Chem. Chem. Phys. 2007, 9, 3397

(32) Jurečka, P.; Cerný, J.; Hobza, P.; Salahub, D. R. J. Comput. Chem. 2007, 28, 555 .

(33) Becke, A. D.; Johnson, E. R. J. Chem. Phys. 2007, 127, 154108

(34) Becke, A. D.; Johnson, E. R. J. Chem. Phys. 2007, 127, 124108.

(35) von Lilienfeld, O. A.; Tavernelli, I.; Rothlisberger, U. Phys. Rev Lett. 2004, 93, 153004.

(36) Lochan, R. C.; Jung, Y.; Head-Gordon, M. J. Phys. Chem. A 2005, $109,7598$.

(37) Stephens, P. J.; Devlin, F. J.; Chablowski, C. F.; Frisch, M. J. J. Phys. Chem. 1994, 98, 11623.

(38) Hertwig, R. H.; Koch, W. Chem. Phys. Lett. 1997, 268, 345.

(39) Grimme, S. J. Chem. Phys. 2003, 118, 9095.

(40) Jung, Y.; Lochan, R. C.; Dutoi, A. D.; Head-Gordon, M. J. Chem Phys. 2004, 121, 9793 .

(41) Møller, C.; Plesset, M. Phys. Rev. 1934, 46, 618.

(42) Vahtras, O.; Almlöf, J.; Feyereisen, M. W. Chem. Phys. Lett. 1993, $213,514$.

(43) Weigend, F.; Häser, M. Theor. Chem. Acc. 1997, 97, 331.

(44) DiStasio, R. A., Jr.; Steele, R. P.; Rhee, Y. M.; Shao, Y.; HeadGordon, M. J. Comput. Chem. 2007, 28, 839.

(45) Rhee, Y. M.; DiStasio, R. A., Jr.; Lochan, R. C.; Head-Gordon, M. Chem. Phys. Lett. 2006, 426, 197.

(46) DiStasio, R. A., Jr.; Head-Gordon, M. Mol. Phys. 2007, 105, 1073. (47) Shao, Y.; Fusti-Molnar, L.; Jung, Y.; Kussmann, J.; Ochsenfeld, C.; Brown, S. T.; Gilbert, A. T. B.; Slipchenko, L. V.; Levchenko, S. V.; O’Neill, D. P.; DiStasio, R. A., Jr.; Lochan, R. C.; Wang, T.; Beran, G. J. O.; Besley, N. A.; Herbert, J. M.; Lin, C. Y.; Voorhis, T. V.; Chien, S. H.; Sodt, A.; Steele, R. P.; Rassolov, V. A.; Maslen, P. E.; Korambath, P. P.; Adamson, R. D.; Austin, B.; Baker, J.; Byrd, E. F. C.; Dachsel, H.; Doerksen, R. J.; Dreuw, A.; Dunietz, B. D.; Dutoi, A. D.; Furlani, T. R.; Gwaltney, S. R.; Heyden, A.; Hirata, S.; Hsu, C.-P.; Kedziora, G.; Khalliulin, R. Z.; Klunzinger, P.; Lee, A. M.; Lee, M. S.; Liang, W.; Lotan, I.; Nair, N.; Peters, B.; Proynov, E. I.; Pieniazek, P. A.; Rhee, Y. M.; Ritchie, E. R. J.; Sherrill, C. D.; Simmonett, A. C.; Subotnik, J. E.; Woodcock, H. L., III; Zhang, W.; Bell, A. T.; Chakraborty, A. K.; Chipman, D. M.; Keil, F. J.; Warshel, A.; Hehre, W. J.; Schaefer, H. F., III; Kong, J.; Krylov, A.; Gill, P. M. W.; Head-Gordon, M. Phys. Chem. Chem. Phys. 2006, 8, 3172.

(48) Dunning, T. H., Jr. J. Chem. Phys. 1989, 90, 1007.

(49) Weigend, F.; Köhn, A.; Hättig, C. J. Chem. Phys. 2001, 116, 3175.

(50) Boys, S. F.; Bernardi, F. Mol. Phys. 1970, 19, 553.

(51) Gill, P. M. W.; Johnson, B. G.; Pople, J. A. Chem. Phys. Lett. 1993 209, 506.

(52) Becke, A. D. Phys. Rev. A 1988, 38, 3098.

(53) Lee, C.; Yang, W.; Parr, R. G. Phys. Rev. B 1988, 37, 3098. 
(54) Dombroski, J. P.; Taylor, S. W.; Gill, P. M. W. J. Phys. Chem. 1996, $100,6272$.

(55) Hetzer, G.; Schutz, M.; Stoll, H. J. Chem. Phys. 2000, 113, 9443. (56) Leininger, T.; Stoll, H.; Werner, H.-J.; Savin, A. Chem. Phys. Lett. 1997, 275, 151 .

(57) Lochan, R. C.; Shao, Y.; Head-Gordon, M. J. Chem. Theory Comput. 2007, 3, 988.

(58) Jung, Y.; Head-Gordon, M. Phys. Chem. Chem. Phys. 2006, 8, 2831 (59) Curtiss, L. A.; Raghavachari, K.; Redfern, P. C.; Pople, J. A. J. Chem. Phys. 1997, 106, 1063.

(60) Curtiss, L. A.; Raghavachari, K.; Redfern, P. C.; Pople, J. A. J. Chem. Phys. 1991, 94, 7221.

(61) Ernzerhof, M.; Scuseria, G. E. J. Chem. Phys. 1999, 110, 5029

(62) Jurečka, P.; Šponer, J.; Černý, J.; Hobza, P. Phys. Chem. Chem. Phys. 2006, 8, 1985.

(63) Grimme, S. Angew. Chem., Int. Ed. 2006, 45, 4460.

(64) Hyla-Krispin, I.; Grimme, S. Organometallics 2004, 23, 5581.

(65) Schultz, N. E.; Zhao, Y.; Truhlar, D. G. J. Phys. Chem. A 2005, 109,4388 .
(66) Zhao, Y.; Lynch, B. J.; Truhlar, D. G. Phys. Chem. Chem. Phys. $\mathbf{2 0 0 5}, 7,43$.

(67) Zhao, Y.; Gonzàlez-Garcìa, N.; Truhlar, D. G. J. Phys. Chem. A 2005, 109, 2012.

(68) Tsuzuki, S.; Lüthi, H. P. J. Chem. Phys 2001, 114, 3949.

(69) Tsuzuki, S.; Honda, K.; Uchimaru, T.; Mikami, M.; Tanabe, K. J. Am. Chem. Soc. 2000, 122, 3746.

(70) Tsuzuki, S.; Honda, K.; Uchimaru, T.; Mikami, M.; Tanabe, K. J. Phys. Chem. A 2002, 106, 4423.

(71) Jurečka, P.; Hobza, P. Chem. Phys. Lett. 2002, 365, 89.

(72) Shavitt, I. Tetrahedron 1985, 41, 1531.

(73) Pu, J.; Truhlar, D. G. J. Phys. Chem. A 2005, 109, 773

(74) Dybala-Defratyka, A.; Paneth, P.; Pu, J.; Truhlar, D. G. J. Phys. Chem. A 2004, 108, 2475.

(75) Lynch, B. J.; Fast, P. L.; Harris, M.; Truhlar, D. G. J. Phys. Chem. A 2000, 104, 4811 .

(76) Huber, K. P.; Herzberg, G. Constants of Diatomic Molecules, Molecular Spectra and Molecular Structure; Van Nostrand, Princeton, NJ, 1979; Vol. 4 